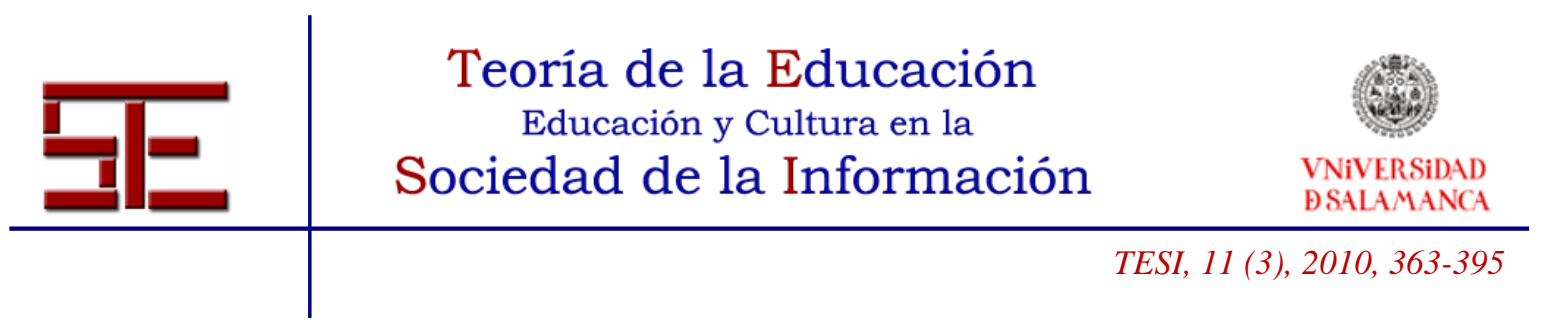

\title{
PERCEPCIONES DEL E-LEARNING DESDE LA PERSPECTIVA DE LOS RESPONSABLES TÉCNICOS DE UNIVERSIDAD ${ }^{1}$
}

Resumen: La mayoría de las investigaciones que nos encontramos referentes a la incorporación de las TICs y el eLearning en las universidades están enfocadas a conocer la opinión de profesores y estudiantes que sobre la misma poseen. En esta ocasión, y con el siguiente artículo, realizamos la investigación desde la perspectiva de los responsables técnicos de universidad, para conocer cómo perciben ellos este proceso de incorporación. En definitiva, conocer los motivos que se están llevando a cabo desde la universidad para adoptar acciones formativas semipresenciales, qué medidas se están adoptando para resolver dificultades, y como se están llevando a cabo; es decir, se trataba de recoger las visiones que sobre el proceso de implantación de la formación en red tenían los responsables técnicos directos de estas acciones formativas. El interés mostrado por el profesorado y alumnado, o la falta de formación por parte del profesorado, son algunas conclusiones obtenidas a través del estudio realizado.

Palabras clave: Educación a distancia; aprendizaje semipresencial; buenas prácticas; educación superior; métodos de enseñanza; investigación educativa.

${ }^{11}$ La presente investigación forma parte del Proyecto de Excelencia PO7-SE-J.02670, denominado "Usos del e-learning en las Universidades Andaluzas: estado de la situación y análisis de buenas prácticas" financiado por la Secretaría General de Universidades, Investigación y Tecnología de la Junta de Andalucía.

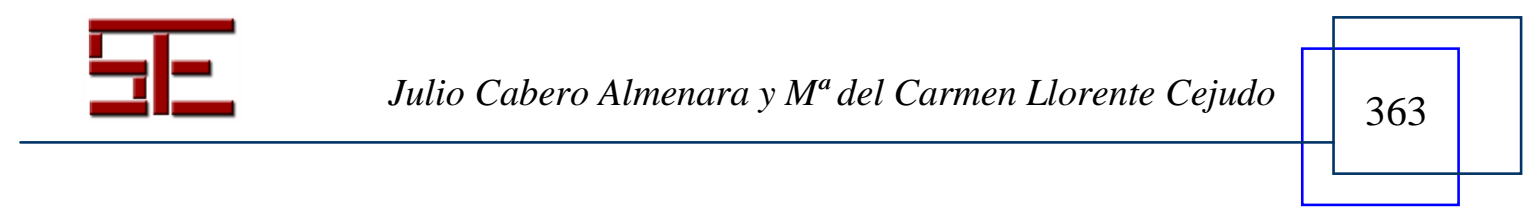




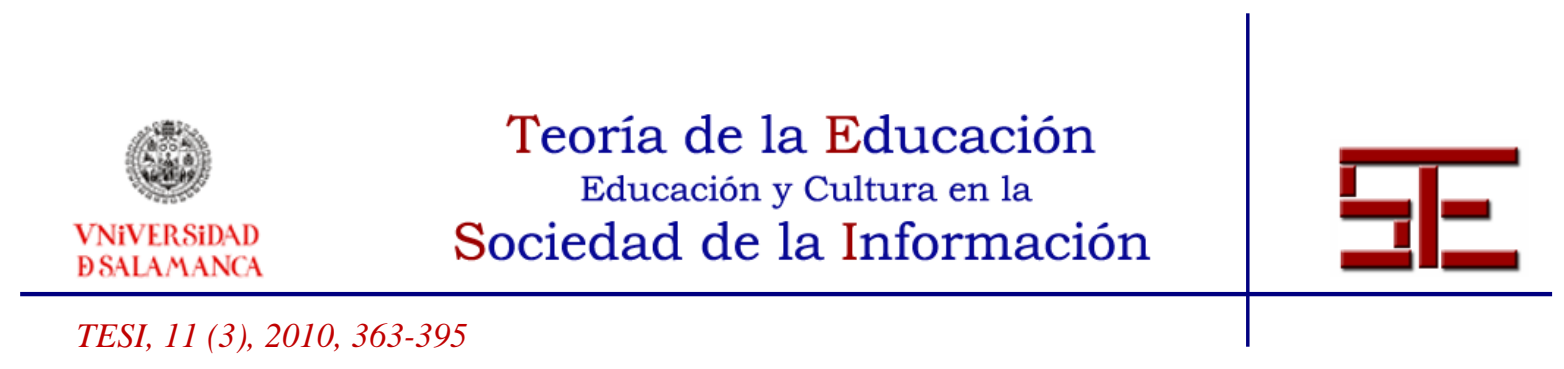

\section{ELEARNING PERCEPTIONS FROM THE PERSPECTIVE OF THE RESPONSIBLE TECHNICIANS AT UNIVERSITY}

Abstract: Most of investigations that we are relating to the incorporation of the ITC and eLearning at universities are focused to know the opinion of professors and students that it has more than enough the same one they possess. In this occasion, and with the following article, we carry out the research from the university technician's perspective, to know how they perceive this incorporation process. Definitively, to know the reasons that are carrying out from the university to adopt blended learning formative actions, how measures are adopting to solve difficulties, and like they are carrying out; in other words, it was to pick up the visions that it has more than enough the process of incorporation of the formation in net had the responsible direct technicians of these formative actions. The interest shown by the faculty and student, or the training necessity by professor, they are some conclusions obtained through the carried out study.

Keywords: Distance education; blended learning; best practices; higher education; teaching methods; educational research.

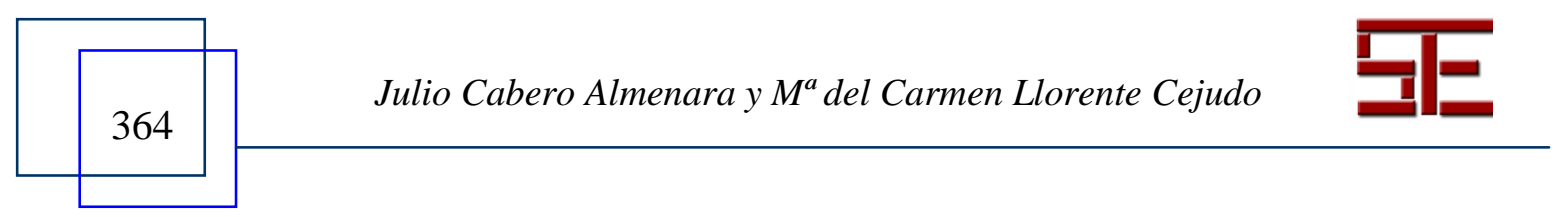




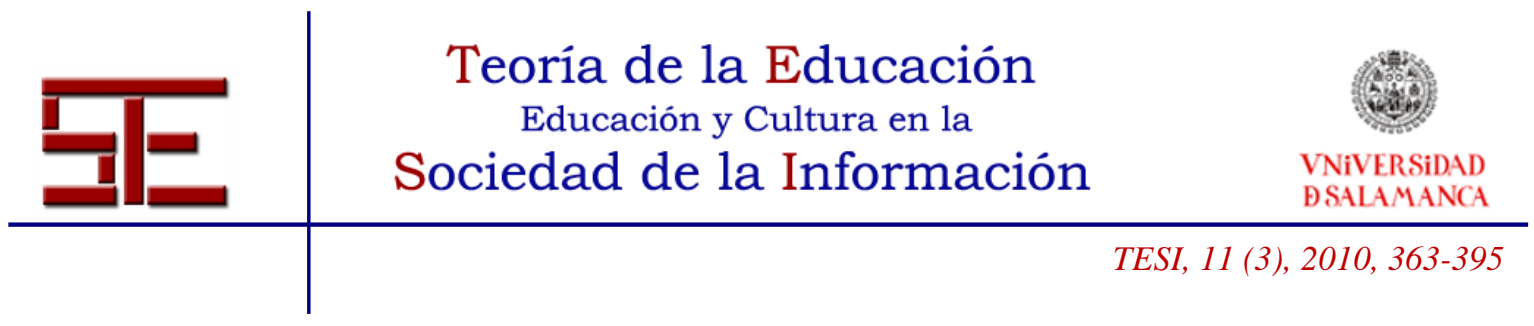

\title{
PERCEPCIONES DEL E-LEARNING DESDE LA PERSPECTIVA DE LOS RESPONSABLES TÉCNICOS DE UNIVERSIDAD
}

Fecha de recepción: 02/06/2010; fecha de aceptación: 07/09/2010; fecha de publicación: 30/11/2010

\author{
Julio Cabero Almenara \\ cabero@us.es \\ Universidad de Sevilla \\ $\mathrm{M}^{\mathrm{a}}$ del Carmen Llorente Cejudo \\ karen@us.es \\ Universidad de Sevilla
}

\section{1.- LAS VISIONES DE LOS PARTICIPANTES EN LAS ACCIONES DEL E- LEARNING}

Los agentes participantes en acciones de e-learning no son solamente los profesores y los alumnos, como tradicionalmente se ha considerado y contemplado en la investigación educativa, sino que también intervienen los profesionales técnicos que las universidades movilizan para que estas acciones puedan llevarse a cabo. Profesionales que suelen cumplir diferentes funciones, que van desde el mantenimiento de las redes telemáticas, la adquisición y sostenimiento de los servidores y teleplataformas utilizadas por las universidades, la puesta en acción de políticas para la capacitación del profesorado y el alumnado en el e-learning o la construcción de libros de estilos para el diseño de materiales uniformes y de calidad por parte de los profesores, entre otras.

Como señalamos en un trabajo sobre los usos que del e-learning se hacía en las diferentes universidades andaluzas (Benítez y Aguilar, 2010; Cabero, 2010), en todas ellas se habían creado servicios e instituciones específicas para favorecer su implantación que desempeñaban una serie de funciones y objetivos, tales como: ofrecer a toda la comunidad universitaria la plena incorporación del Campus Virtual en el desarrollo del proceso de enseñanza-aprendizaje; contribuir a la mejora de los procesos de enseñanza-aprendizaje a través de una mejor formación del profesorado y del alumnado en materias de utilización didáctica-pedagógica y comunicativa de las Tecnologías de la Información y la Comunicación (TIC) de forma que se les facilite el trabajo semipresencial, las tutorías virtuales, etc.; introducir el desarrollo de las TIC en el papel de la educación superior mostrando al profesorado las ventajas e inconvenientes pedagógicos de éstas y ayudando al estudiante a comprender las capacidades de su inteligencia mediante un modelo enfocado al aprendizaje; facilitar a los estudiantes

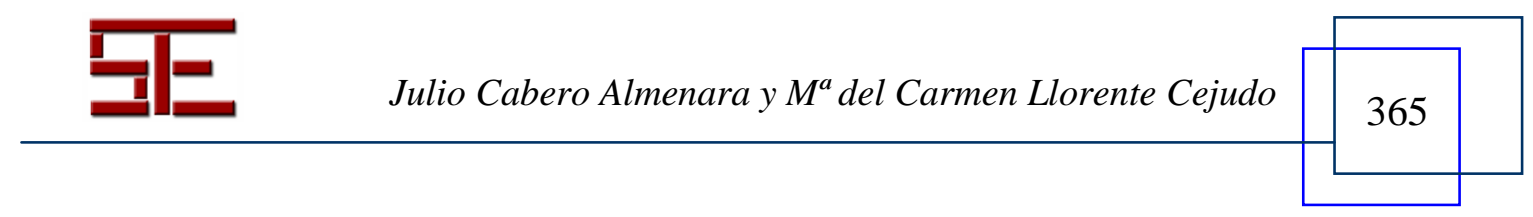




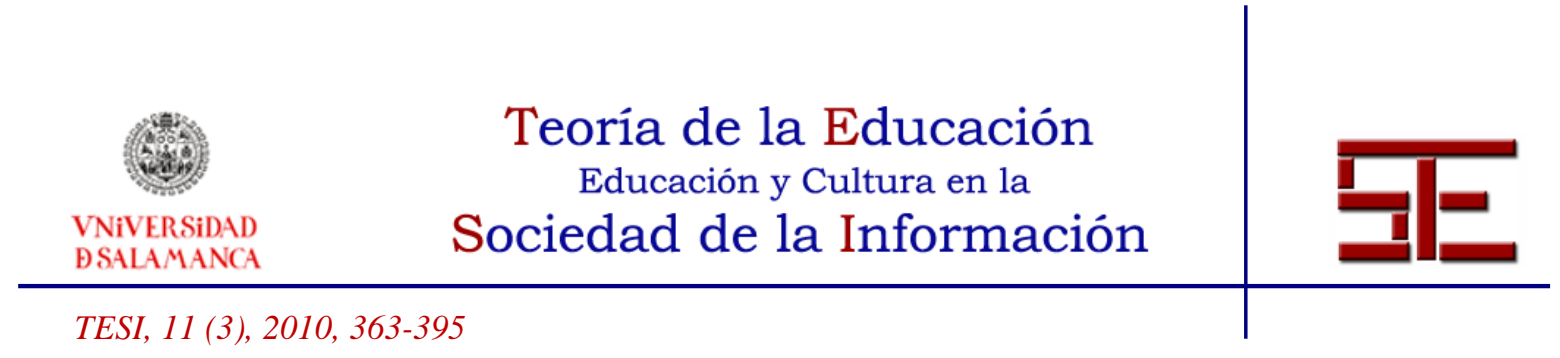

mejores materiales multimedia que faciliten distintos ritmos de trabajo y eliminen barreras vinculadas al espacio y al tiempo; facilitar el proceso de adaptación de la universidad presencial a un modelo organizativo flexible; dotar al Campus universitario de tecnología wifi; producción de materiales didácticos universitarios distribuidos en red; planificar, diseñar y ejecutar las adquisiciones de material informático (equipos, programas y servicios) del conjunto de la Universidad; planificar, diseñar y coordinar la instalación y operación de las aulas informáticas, facilitando al conjunto de alumnos el acceso a los sistemas y servicios informáticos; atender las consultas y demandas de intervención individualizada sobre el material informático y de comunicaciones (instalación, operación y mantenimiento de equipos, programas y servicios); crear y fomentar la docencia no presencial a través de la "Universidad Virtual"; diseñar, desarrollar y mantener un espacio de apoyo al profesorado para elaborar y difundir materiales didácticos así como fomentar la teletutorización; y, por último, gestión e implantación de aplicaciones de red.

Tal necesidad de estos aspectos técnicos y organizativos se ha puesto de manifiesto desde diferentes investigaciones, tanto nacionales como internacionales, al indicar que para los profesores el apoyo institucional y tecnológico recibido es una de las variables que caracteriza el éxito de estas acciones formativas, convirtiéndose en el caso contrario en un factor inhibidor (Correa, 2004; Pérez, 2007; Duart y otros, 2008; Bollinger y Wasiliski, 2009; Gannon y otros, 2009; Cabero y Romero, 2010).

De todas formas, ya comienzan a realizarse diferentes propuestas como la de Conole y Oliver (2007), que abren el abanico de áreas de investigación haciendo referencia a las áreas: 1) Pedagógica, 2) Técnica, 3) Organizativa y 4) Factores socioculturales. Lo que nos referimos se encontraría a medio camino entre la referida a aspectos técnicos y organizativos, pues de acuerdo con estos autores la primera se centrará en el estudio de la arquitectura tecnológica utilizada para soportar diferentes formas de aprendizaje, los mecanismos utilizados para monitorizar las actividades de formación on-line, o las diferentes formas de presencial virtual. En contrapartida la organizativa se preocupa por la investigación de las estrategias efectiva para la puesta en acción de la formación virtual, el desarrollo del conocimiento organizativo y los diferentes procesos puestos en funcionamiento para su incorporación.

Resulta llamativo que frente al papel tan significativo que suelen desempeñar, pocos son los estudios e investigaciones en los que se ha pretendido recoger la opinión que estos profesionales tienen de cómo se está utilizando el e-learning en las universidades y las propuestas que harían para mejorar su incorporación y solucionar los diferentes problemas detectados.

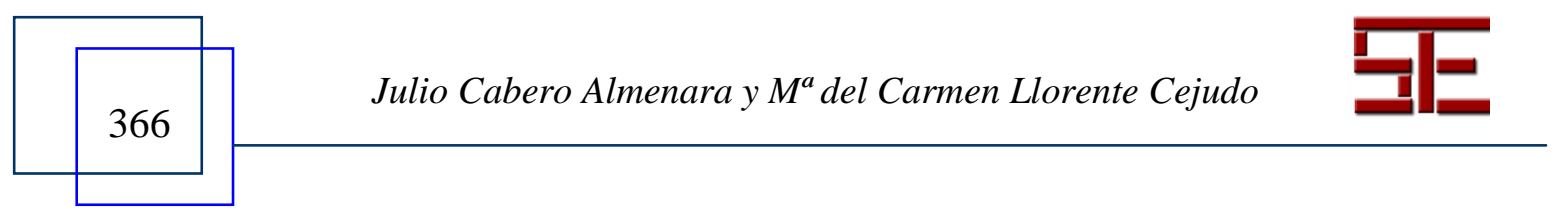




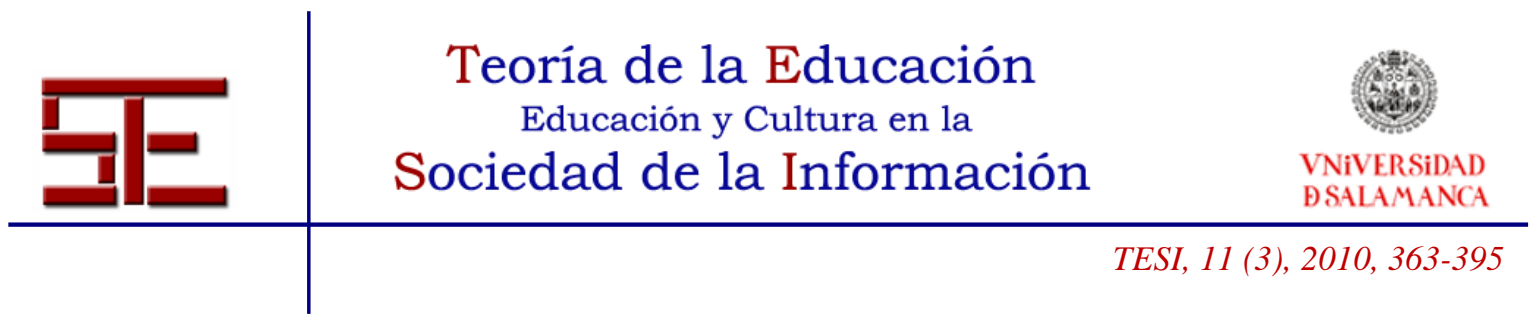

En contrapartida con lo que estamos comentando, nos encontramos con un escaso número de investigaciones donde se les ha preguntado a estos profesionales respecto a las opiniones que tienen en relación a la incorporación del e-learning, y éste ha sido uno de los argumentos que más nos ha movilizado para llevar a cabo la investigación.

\section{2.- METODOLOGÍA DEL ESTUDIO}

Con nuestra investigación pretendimos recoger información respecto a "cómo percibían los responsables de las Universidades que implementaban las acciones de e-learning y b-learning las acciones formativas se estaban implantando, qué problemas se habían encontrado en su implantación, cuáles creían que eran los principales motivos que estaban llevando a la adopción por las Universidades de acciones formativas de este tipo, qué medidas desde la institución se habían adoptado para resolverlas, y cómo se estaban llevando a cabo"; es decir, se trataba de recoger las visiones que sobre el proceso de implantación de la formación en red tenían los responsables técnicos directos de estas acciones formativas.

Tenemos que señalar que cuando hablamos de responsables asumíamos que podían serlo a diferentes niveles: a) Técnico/Instrumental, b) Didáctico/diseño de materiales, y c) Formación del profesorado. Y a ellos fue a los que entrevistamos en las Universidades de Sevilla, Pablo Olavide, Huelva, Jaén, Cádiz y Málaga. No quisimos entrevistar a los responsables que podríamos denominar políticos (Vicerrectores de Nuevas Tecnologías), por una serie de motivos: dificultades que muchas veces entraña la contemplación de citas con estas personas por motivos de agenda, y preferir obtener información de personas más cercanas a la realidad, a la práctica, y a la organización educativa. Indicar que el número total de entrevistas que se realizaron fueron 13.

El tipo de entrevista que seleccionamos fue la semiestructurada (Albert, 2007, 245) aplicando el protocolo que exponemos a continuación y discriminando los diferentes tipos de responsables técnicos con los cuales nos podríamos encontrar:

Protocolo de entrevista para los responsables técnicos

- ¿A qué institución pertenece usted?

- ¿Cómo se está desarrollando la implantación de la formación virtual en su Universidad?

- ¿Qué resultados cree que se están obteniendo?

- ¿Cómo ha sido aceptado por el profesorado?

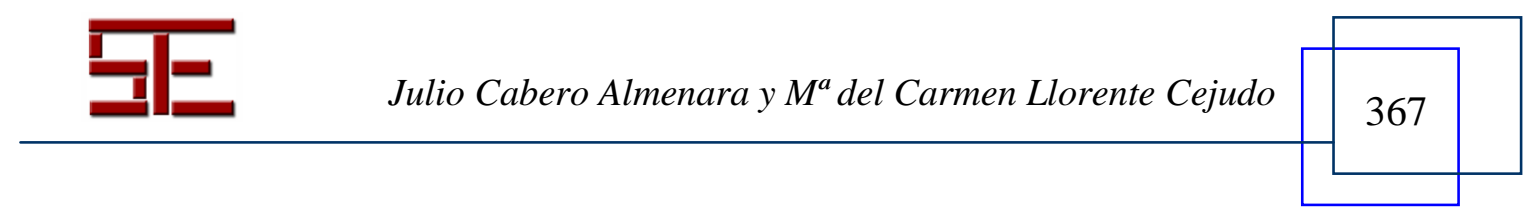




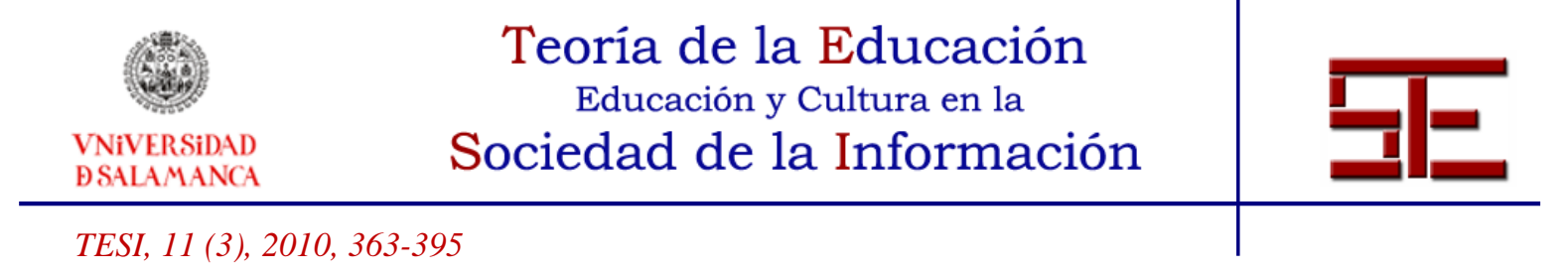

- ¿Qué medidas de tipo técnico se han adoptado para facilitar su introducción?

- ¿Con qué problemas de tipo técnico se han encontrado y cómo los han resuelto?

- ¿Se han apoyado en algunas empresas externas?

- ¿Por qué se eligió la plataforma de LMS que utilizan?

- ¿Cuáles considera usted que son las mejores "buenas prácticas" que se están desarrollando en su Universidad por parte de algún profesor concreto?

- ¿Qué ayudas ha recibido el profesorado para su incorporación a la formación virtual?

- ¿Qué ayudas ha recibido el alumnado para su formación virtual?

- Institucionalmente, ¿quiénes son los responsables de la formación virtual en su Universidad?

\section{$\underline{\text { Protocolo de entrevista para los responsables didácticos/diseño de materiales }}$}

- ¿A qué institución pertenece usted?

- ¿Cómo se está desarrollando la implantación de la formación virtual en su Universidad?

- ¿Qué resultados cree que se están obteniendo?

- ¿Cómo ha sido aceptado por el profesorado?

- ¿Qué medidas de tipo didáctico y para el diseño de materiales se han adoptado para facilitar su introducción?

- ¿Se han apoyado en algunas empresas externas para facilitar la producción de materiales didácticos por parte de los profesores?

- ¿Cuáles considera usted que son las mejores "buenas prácticas" que se están desarrollando en su Universidad por parte de algún profesor concreto?

- ¿Cuál es la actitud del profesorado hacia la producción de estos materiales?

- ¿Qué ayudas ha recibido el profesorado para su incorporación a la formación virtual?

- ¿Qué ayudas ha recibido el alumnado para su formación virtual?

- Institucionalmente, ¿quiénes son los responsables de la formación virtual en su Universidad?

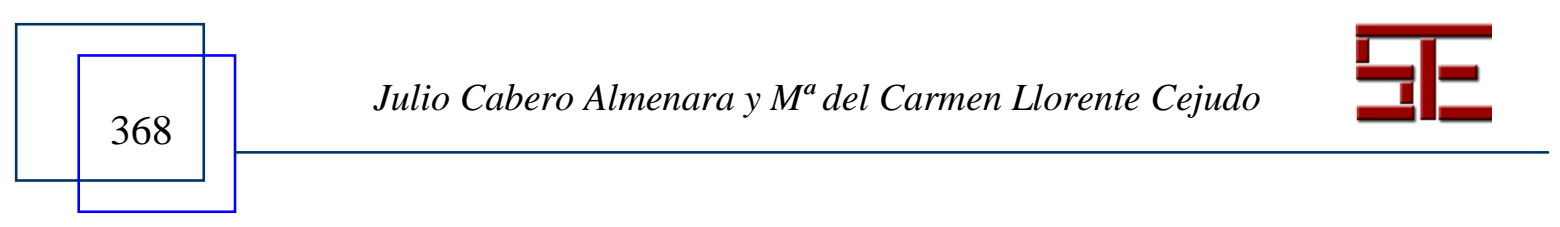




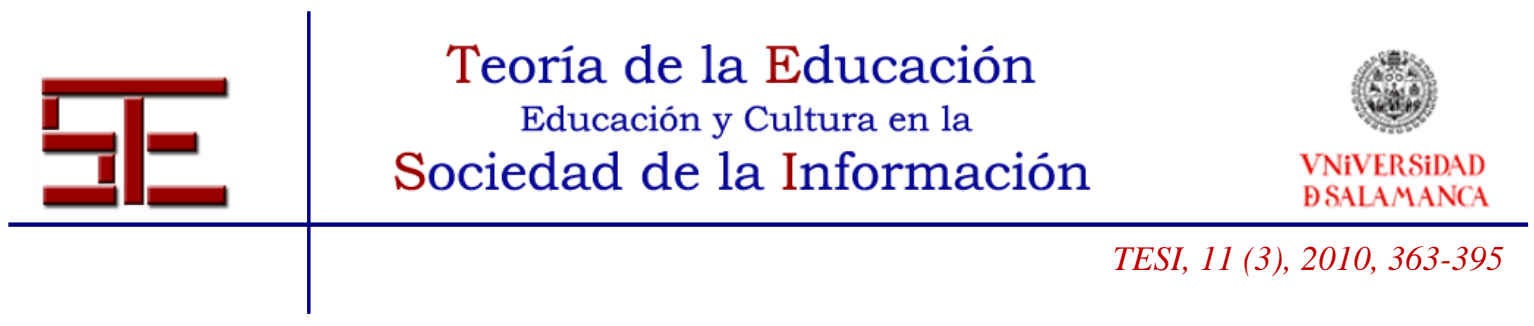

- ¿Se ha elaborado algún material formativo de apoyo para el profesorado? Guías de buenas prácticas, libros de estilos de producción de material educativo, aplicación de estrategias metodológicas en la formación virtual, etc.

\section{$\underline{\text { Protocolo de entrevista para los responsables de la formación del profesorado }}$}

- ¿A qué institución pertenece usted?

- ¿Cómo se está desarrollando la formación del profesorado para la enseñanza virtual en su Universidad?

- ¿Qué valoración hace sobre la capacidad del profesorado de su Universidad para la incorporación de la formación virtual en su práctica educativa?

- ¿En qué han consistido, fundamentalmente, las actividades de formación del profesorado para la enseñanza virtual que se han realizado en su Universidad?

- ¿Cuáles considera usted que son las mejores "buenas prácticas" que se están desarrollando en su Universidad por parte de algún profesor concreto?

- ¿Qué ayudas ha recibido el profesorado para su incorporación a la formación virtual?

- ¿Qué ayudas ha recibido el alumnado para su formación virtual?

- Institucionalmente, ¿quiénes son los responsables de la formación virtual en su Universidad?

- ¿Se ha elaborado algún material formativo de apoyo para los profesores? Guías de buenas prácticas, libros de estilos de producción de material educativo, aplicación de estrategias metodológicas en la formación virtual, etc.

- ¿Se ha llevado a cabo alguna investigación/evaluación de la experiencia?

En la organización de las fases operativas, tuvimos en cuenta las fases en las que tradicionalmente se aplica el análisis de contenido: preanálisis, formación del sistema de categorías y codificación y análisis (Bardin, 1986).

\section{A) Preanálisis}

En esta fase adoptamos una serie de decisiones en función de los objetivos que perseguimos en la investigación, en concreto: diseñar el instrumento y elaborar el

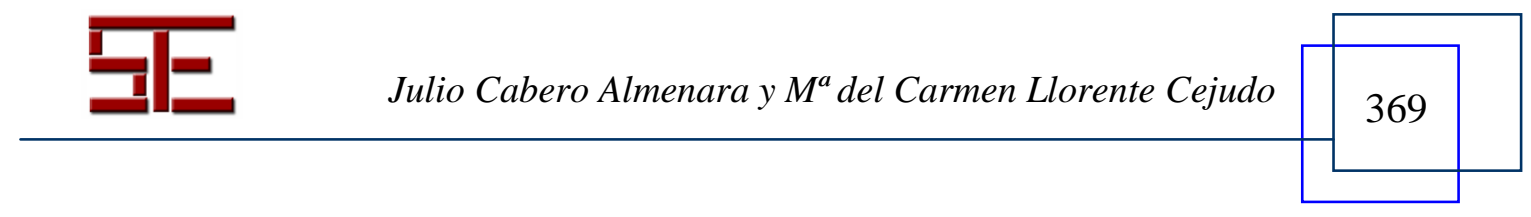




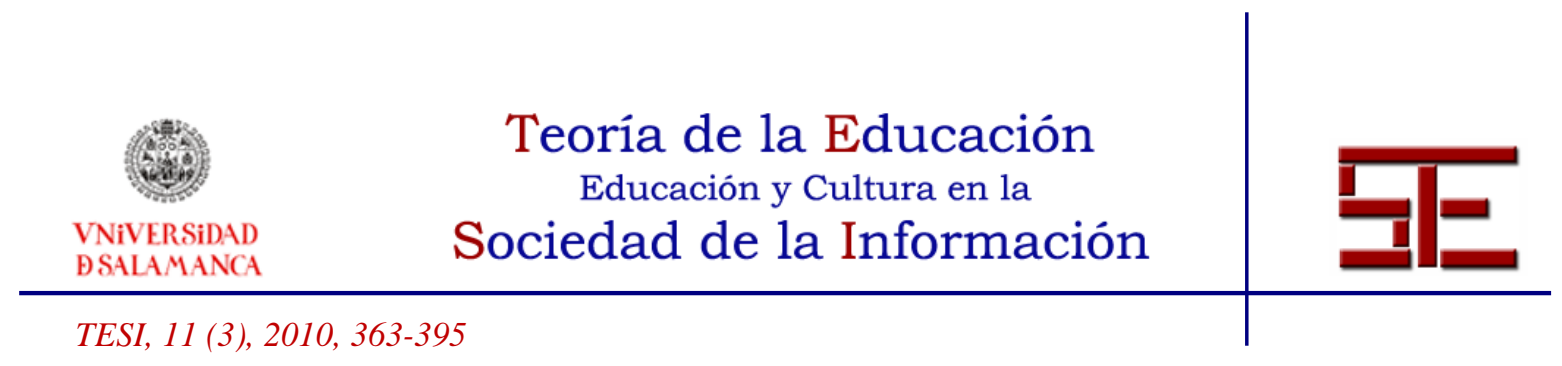

protocolo, y determinar la muestra a la cual se le efectuará la entrevista. En esta fase también se realizó el primer contacto con los textos obtenidos tras la realización de la entrevista y sobre los que se aplicará el análisis de contenido.

B) Formación de los Sistemas de Categorías

La formación del Sistema de Categorías es la fase más significativa de la técnica que analizamos, y tal como indica Anderson (1994), ésta es la parte más importante de la investigación ya que refleja directamente el propósito del investigador y la teoría subyacente que organiza el estudio. El crear un Sistema de Categorías requiere un proceso constante de identificación-selección y reagrupamiento de elementos aislados, de manera que conforme se vaya avanzando en la construcción del Sistema las más débiles conceptualmente se reagruparán en categorías o dimensiones más generales y estables. Estas categorías pueden ser establecidas por el investigador a partir de diferentes vías como la revisión teórica y conceptual de su objeto de estudio, otros sistemas de categorías previos, opiniones de expertos y especialistas y un acercamiento a los textos de análisis (Pérez Serrano, 1984; Bardín, 1986; Clemente y Santalla, 1991). Señalar que nosotros nos apoyamos en el protocolo realizado y en la lectura de los textos.

Para facilitar la posterior codificación por los codificadores realizamos una guía de ayuda (Postic y De Ketele, 1992) donde se definían las categorías utilizadas y se ejemplificaban con fragmentos de textos del propio documento a analizar; además de las previas discusiones en grupo.

Para la elaboración del Sistema de Categorías que determinaría nuestras unidades de significado se efectuaron las siguientes fases: (a) lectura inicial de las entrevistas de la que se sacó un primer borrador de las categorías; (b) el análisis de las preguntas que conformaban el protocolo de las entrevistas, y, por último, (c) la revisión de otros Sistemas de Categorías ya existentes. Tras ello se estableció el primer Sistema de Categorías que perfilamos a medida que ensayamos la codificación con algunas entrevistas, pues en ambas hubo que añadir códigos nuevos para poder recoger la totalidad de los comentarios efectuados en las grandes dimensiones.

El sistema categorial elaborado estaba formado por siete grandes dimensiones y diferentes categorías incorporadas en las mismas. En la Tabla $n^{\circ} 1$ se presentan las mismas, así como la definición adoptada para la categoría y un ejemplo de la misma.

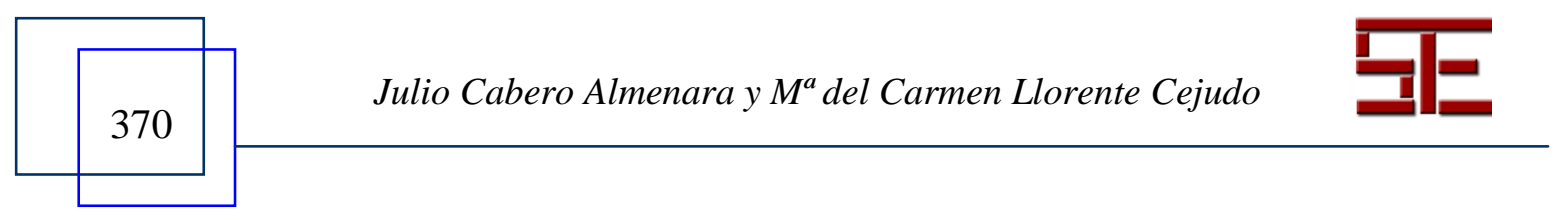




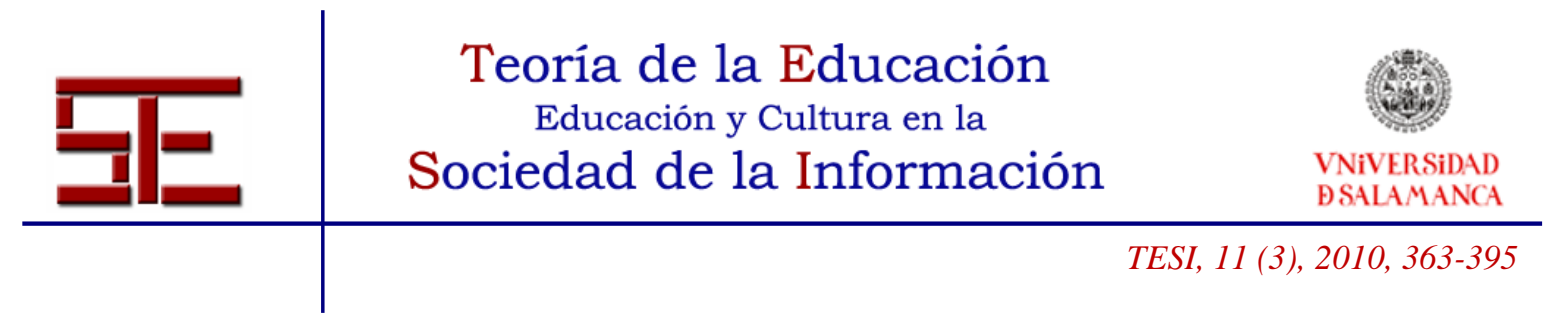

\begin{tabular}{|c|c|c|c|}
\hline DIMENSIONES & CATEGORÍAS & DEFINICIÓN & EJEMPLOS \\
\hline Instituciones & Institución & $\begin{array}{l}\text { Institución responsable } \\
\text { del proceso de } \\
\text { implantación de la } \\
\text { formación virtual }\end{array}$ & $\begin{array}{l}\text { "A la universidad de Cádiz". } \\
(P: 6)\end{array}$ \\
\hline Tiempo & Tiempo & $\begin{array}{l}\text { Tiempo de } \\
\text { implantación del } \\
\text { proceso de F.V. }\end{array}$ & $\begin{array}{l}\text { "Ehh, desde el 2001, creo que } \\
\text { fue, desde el 2002-2001, ehh, se } \\
\text { están desarrollando enseñanza } \\
\text { virtual en la universidad" (P.2) }\end{array}$ \\
\hline \multirow{4}{*}{$\begin{array}{c}\text { Desarrollo de la } \\
\text { Formación Virtual } \\
(F . V .)\end{array}$} & Motivos & $\begin{array}{l}\text { Motivación para la } \\
\text { puesta en } \\
\text { funcionamiento del } \\
\text { proceso de F.V. }\end{array}$ & $\begin{array}{l}\text { "Se trataba de producir, ehh, } \\
\text { de llevar asignaturas a la red } \\
\text { para fomentar su impartición } \\
\text { virtual o más correctamente, su } \\
\text { impartición mediante Blende- } \\
\text { learning". (P11) }\end{array}$ \\
\hline & $\begin{array}{l}\text { Responsables de la } \\
\text { formación }\end{array}$ & $\begin{array}{l}\text { Persona o institución } \\
\text { responsable del } \\
\text { proceso de F.V. }\end{array}$ & $\begin{array}{l}\text { "Profesores universitarios que } \\
\text { están especialmente } \\
\text { entrenados". (P6) }\end{array}$ \\
\hline & Apoyo empresa externa & $\begin{array}{l}\text { Información relativa a } \\
\text { la existencia de apoyo } \\
\text { externo en el desarrollo } \\
\text { del proceso de F.V. }\end{array}$ & $\begin{array}{l}\text { "Nosotros y alguna universidad } \\
\text { de allí trabajan con Sadiel en } \\
\text { cuanto apoyo." (P2) }\end{array}$ \\
\hline & Apoyo institucional & $\begin{array}{l}\text { Información sobre el } \\
\text { apoyo que se ha } \\
\text { llevado a cabo desde la } \\
\text { propia institución en el } \\
\text { desarrollo del proceso } \\
\text { de formación virtual }\end{array}$ & $\begin{array}{l}\text { "Tenemos abierto un servicio } \\
\text { de consultoría de gestión de } \\
\text { contenido, en la escuela hay } \\
\text { cinco personas contestando las } \\
\text { dudas sobre unas cuarenta } \\
\text { herramientas de gestión de } \\
\text { contenido". (P6) }\end{array}$ \\
\hline
\end{tabular}

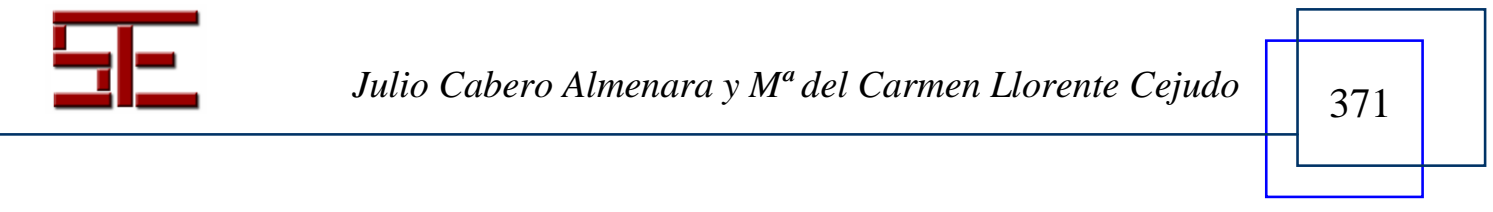




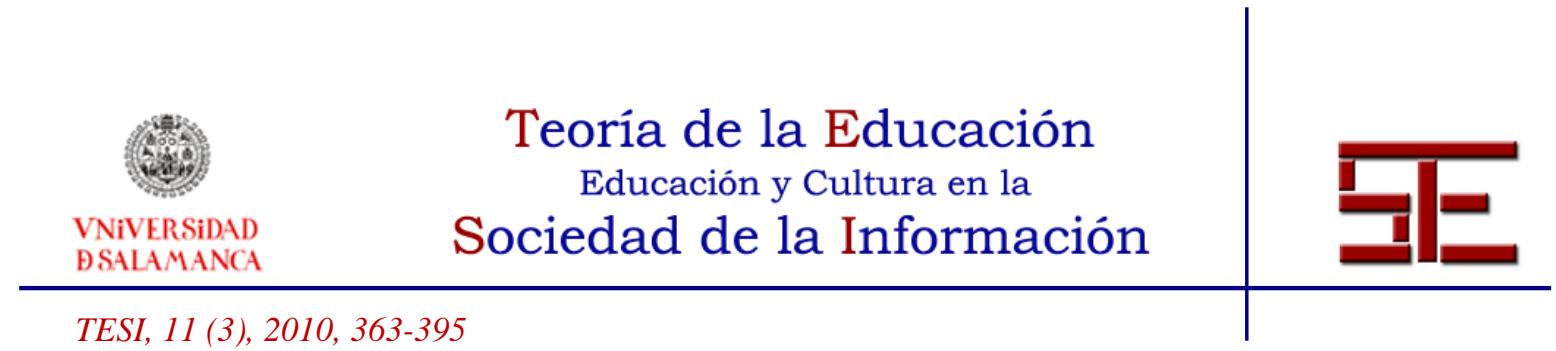

\begin{tabular}{|c|c|c|c|}
\hline DIMENSIONES & CATEGORÍAS & DEFINICIÓN & EJEMPLOS \\
\hline \multirow{5}{*}{$\begin{array}{l}\text { Desarrollo de la } \\
\text { Formación Virtual } \\
(\text { F.V.) }\end{array}$} & Planificación & $\begin{array}{l}\text { Conjunto de pasos que } \\
\text { se establecen para el } \\
\text { desarrollo del proceso } \\
\text { de F.V. }\end{array}$ & $\begin{array}{l}\text { "Se empezaba a hacer una } \\
\text { serie de cursos, donde el } \\
\text { profesor primero aprendía la } \\
\text { plataforma de enseñanza } \\
\text { virtual como es webCT que } \\
\text { utiliza Huelva y luego se } \\
\text { extendía con un curso avanzado } \\
\text { de } 16 \text { horas, donde ya se } \\
\text { aprendían aplicaciones para la } \\
\text { virtualización de contenidos, } \\
\text { para la docencia on-line". (P7) }\end{array}$ \\
\hline & Porcentaje de asignaturas & $\begin{array}{l}\text { Número de asignaturas } \\
\text { implicadas en el } \\
\text { proceso de F.V. }\end{array}$ & $\begin{array}{l}\text { "Ahora mismo, hay una dos mil } \\
\text { y pico de asignaturas, } 2020 \\
\text { asignaturas o algo así que, } \\
\text { viene a constituir casi el } 80 \% \\
\text { de las asignaturas de la } \\
\text { UMA.". (P2) }\end{array}$ \\
\hline & $\begin{array}{c}\text { Problemas } \\
\text { didácticos/organizativos }\end{array}$ & $\begin{array}{l}\text { Dificultades de índole } \\
\text { didáctico/organizativa } \\
\text { a la que se enfrenta el } \\
\text { desarrollo de F.V. }\end{array}$ & $\begin{array}{l}\text { "...alumnos son muchos para } \\
\text { una enseñanza virtual, no se } \\
\text { permite desdoblar en varios } \\
\text { grupos..."(P9) }\end{array}$ \\
\hline & Problemas diseño & $\begin{array}{l}\text { Dificultades en el } \\
\text { diseño con las que se } \\
\text { encuentran en el } \\
\text { proceso de } \\
\text { implantación de la F.V. }\end{array}$ & $\begin{array}{l}\text { “...cuesta trabajo metérselo a } \\
\text { los profesores, un alumno ve } \\
\text { muchas asignaturas, si utilizan } \\
\text { los mismos iconos para } \\
\text { representar las mismas cosas, le } \\
\text { es más fácil el aprendizaje. } \\
\text { (P11) }\end{array}$ \\
\hline & Resultados positivos técnicos & $\begin{array}{l}\text { Resultados obtenidos } \\
\text { por los procesos de } \\
\text { implantación de la F.V }\end{array}$ & $\begin{array}{l}\text { “...tenemos un } 95 \% \text { de la } \\
\text { participación de los alumnos y } \\
\text { prácticamente la mitad de las } \\
\text { asignaturas virtualizadas. (P6) }\end{array}$ \\
\hline
\end{tabular}

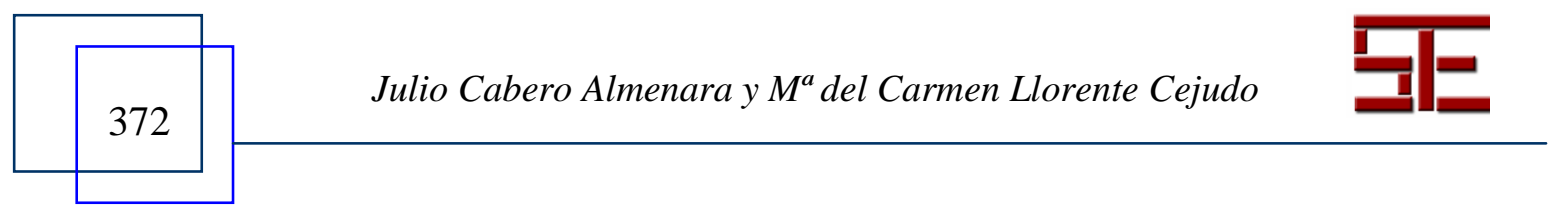




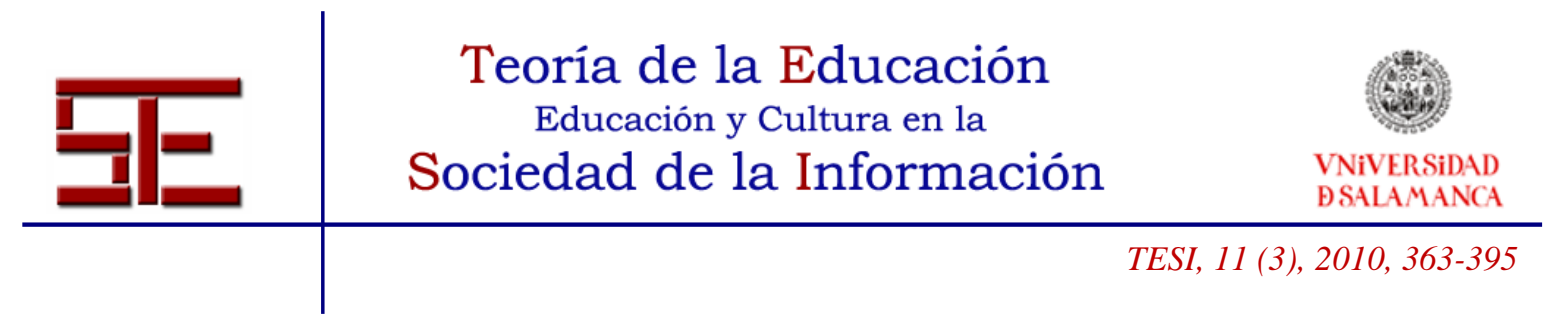

\begin{tabular}{|c|c|c|c|}
\hline DIMENSIONES & CATEGORÍAS & DEFINICIÓN & EJEMPLOS \\
\hline \multirow{5}{*}{ Profesorado } & $\begin{array}{l}\text { Problemas en su } \\
\text { implantación }\end{array}$ & $\begin{array}{l}\text { Dificultades que se han } \\
\text { encontrado en el } \\
\text { proceso de } \\
\text { implantación de la F.V. }\end{array}$ & $\begin{array}{l}\text { "Al principio la gente era } \\
\text { reticente porque decían que en } \\
\text { unos cursos de formación que } \\
\text { se dieron que esto suponía un } \\
\text { tiempo para elaborar materiales, } \\
\text { para colgarlos, para aprender } \\
\text { plataformas, pues que no } \\
\text { tenían." (P9) }\end{array}$ \\
\hline & Formación del profesorado & $\begin{array}{l}\text { Formación que ha } \\
\text { recibido el docente } \\
\text { para el manejo de la } \\
\text { plataforma }\end{array}$ & $\begin{array}{l}\text { "Una batería enorme de cursos } \\
\text { sobre Moodle, WebCT, } \\
\text { herramientas de autoría que } \\
\text { habrán podido ser cien cursos, } \\
\text { en éstos últimos cuatro años" } \\
\text { (P6) }\end{array}$ \\
\hline & Aceptación del profesorado & $\begin{array}{c}\text { La actitud, el interés } \\
\text { del profesor en la } \\
\text { incorporación de la } \\
\text { F.V. }\end{array}$ & $\begin{array}{l}\text { "Entonces, en general, nuestra } \\
\text { impresión y los datos que } \\
\text { tenemos son muy positivos en } \\
\text { el aspecto que está muy } \\
\text { interesada y cada vez vemos } \\
\text { más gente que se está } \\
\text { implicando más en la enseñanza } \\
\text { virtual no porque esté de moda, } \\
\text { no porque le den puntos, sino } \\
\text { porque lo están viendo como } \\
\text { una herramienta fundamental } \\
\text { para su docencia." (P1) }\end{array}$ \\
\hline & Incentivos & $\begin{array}{c}\text { Ayuda que recibe el } \\
\text { profesor para motivarlo } \\
\text { o estimularlo a } \\
\text { incorporarse al proceso } \\
\text { de F.V }\end{array}$ & $\begin{array}{l}\text { "Para profesores que tienen la } \\
\text { docencia... por ejemplo para } \\
\text { los que tienen lo del campus } \\
\text { andaluz virtual o para las } \\
\text { asignaturas de libre } \\
\text { configuración virtuales, se les } \\
\text { reduce la docencia." (P13) }\end{array}$ \\
\hline & Información profesores & $\begin{array}{c}\text { Elaboración de } \\
\text { materiales para apoyar- } \\
\text { orientar al profesor en } \\
\text { el proceso de la F.V }\end{array}$ & $\begin{array}{l}\text { "Se han elaborado guías de } \\
\text { buenos prácticas, pero no } \\
\text { libros, sino pequeñas notas de } \\
\text { dos, tres, cuatro folios, se han } \\
\text { elaborado guías sobre temas de } \\
\text { copy right, de calidad del } \\
\text { material, se han elaborado } \\
\text { manuales de Moodle." }\end{array}$ \\
\hline
\end{tabular}




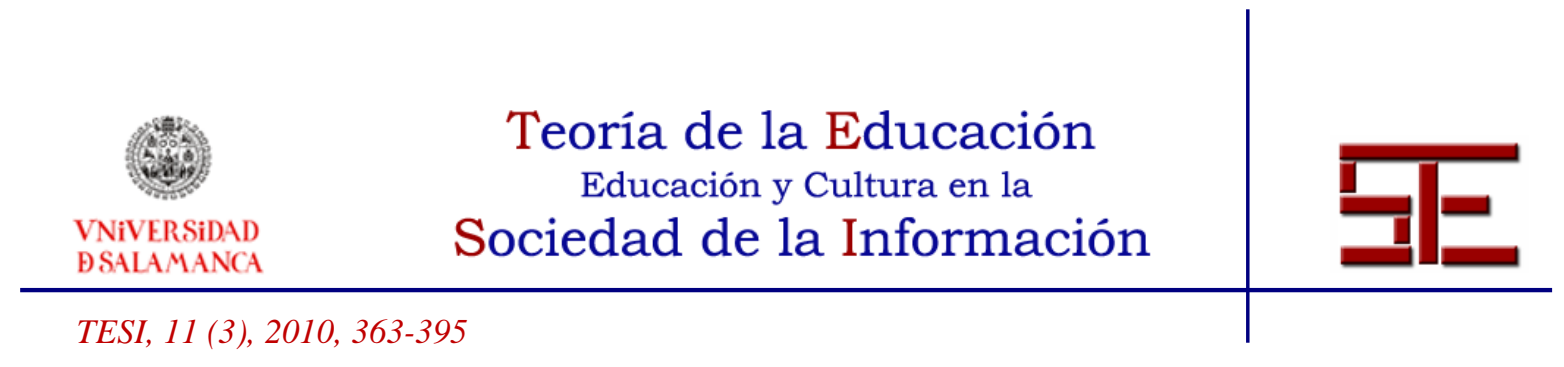

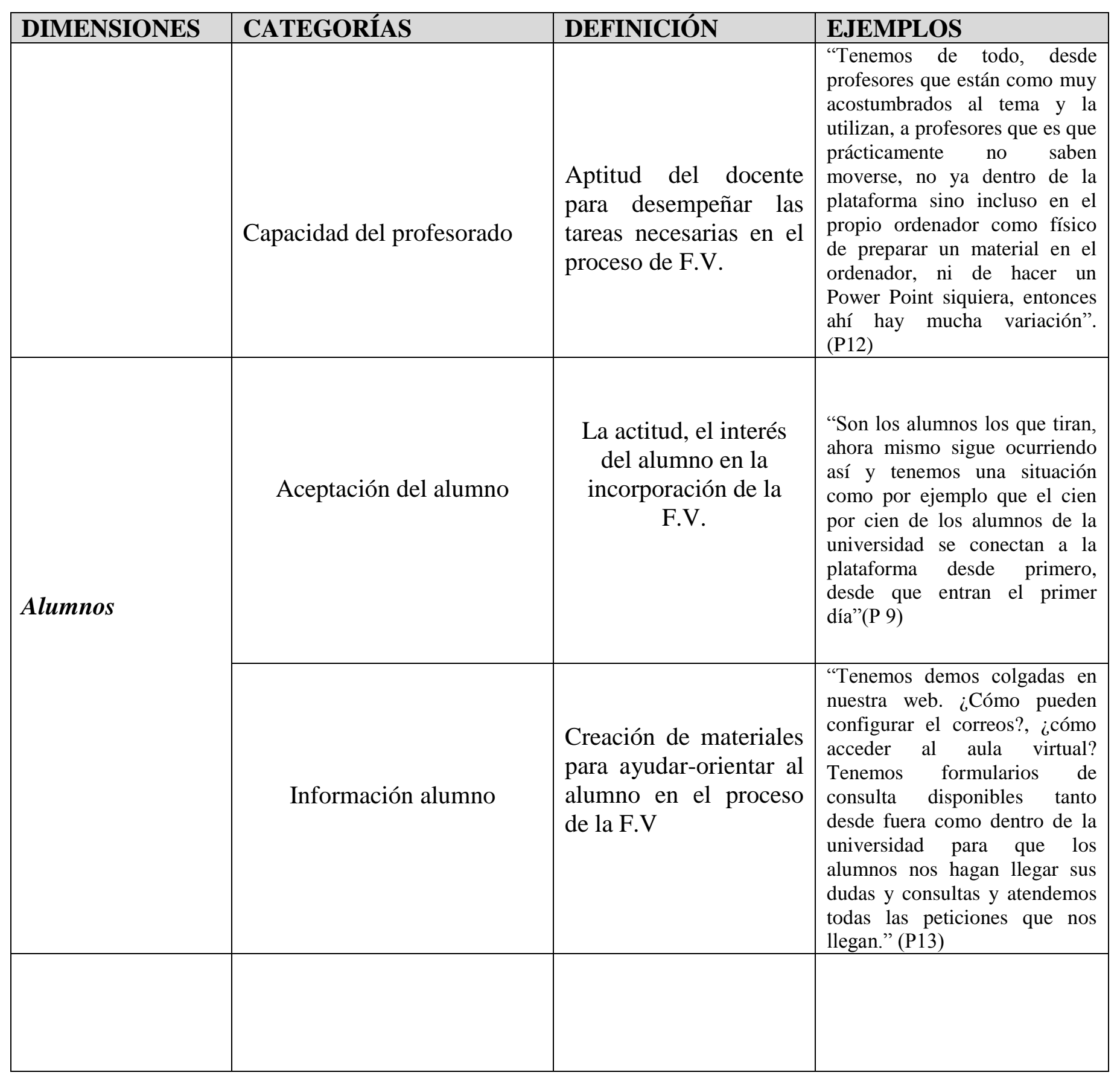

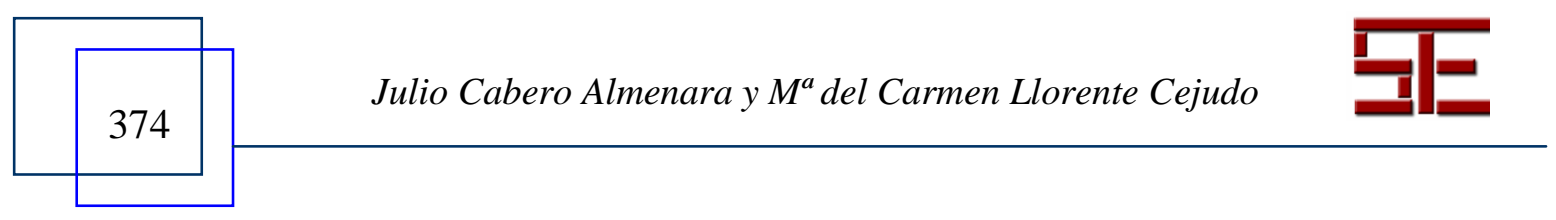




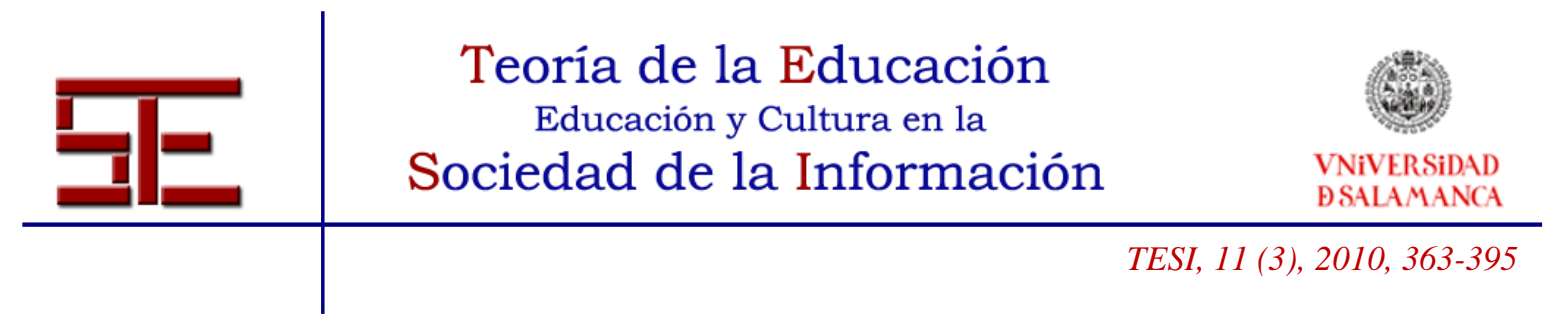

\begin{tabular}{|c|c|c|c|}
\hline DIMENSIONES & CATEGORÍAS & DEFINICIÓN & EJEMPLOS \\
\hline & Buenas prácticas & $\begin{array}{l}\text { Intervenciones } \\
\text { educativas que facilitan } \\
\text { el desarrollo de } \\
\text { actividades de } \\
\text { aprendizaje en las que } \\
\text { se logren con eficiencia } \\
\text { los objetivos } \\
\text { formativos previstos y } \\
\text { también otros } \\
\text { aprendizajes de alto } \\
\text { valor educativo. }\end{array}$ & $\begin{array}{l}\text { "Hay un profesor, González } \\
\text { Pareja, que lleva una asignatura } \\
\text { en económica, que está } \\
\text { haciendo cosas y está digamos } \\
\text { inventando y está } \\
\text { continuamente investigando en } \\
\text { esto. Y entonces, bueno pues } \\
\text { eso, la reflexión sobre ese tipo } \\
\text { de cuestión es interesante" (P1) }\end{array}$ \\
\hline Buenas prácticas & Criterios/ Requisitos & $\begin{array}{l}\text { Condiciones necesarias } \\
\text { para formar parte del } \\
\text { proceso de F.V. }\end{array}$ & $\begin{array}{l}\text { "Estas asignaturas pues tienen } \\
\text { que tener estas características } \\
\text { no, pues emm que tenga una } \\
\text { red de contenidos, unos } \\
\text { recursos de profundización, una } \\
\text { presentación, un mapa } \\
\text { conceptual, que después, } \\
\text { durante, por la navegación el } \\
\text { alumno sepa siempre donde } \\
\text { está, por ejemplo, que es lo que } \\
\text { viene detrás, que es lo que } \\
\text { viene delante". (P1) }\end{array}$ \\
\hline
\end{tabular}

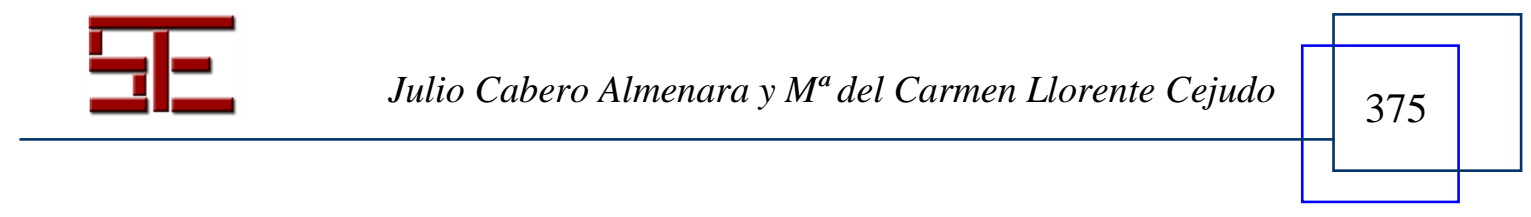




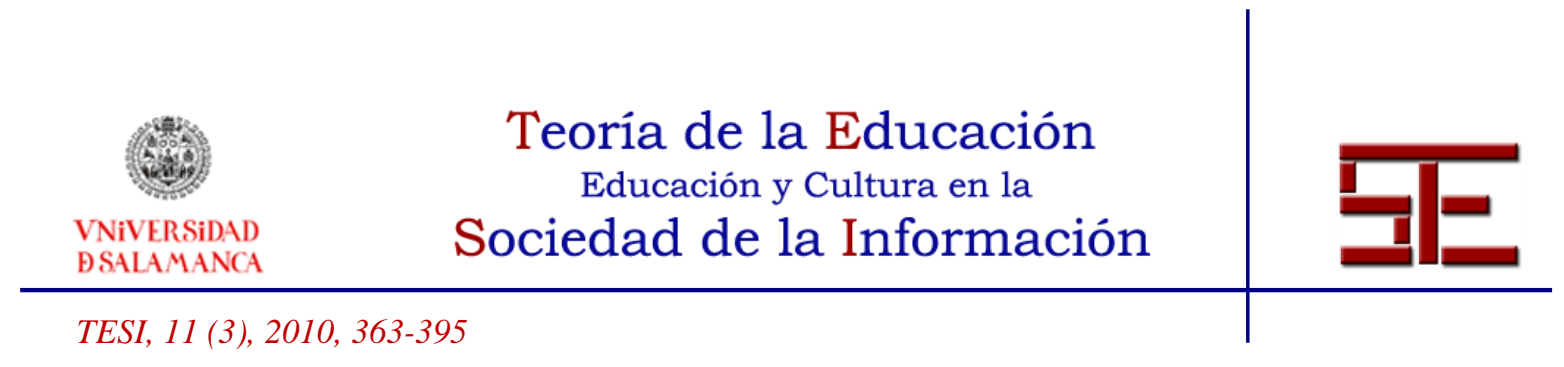

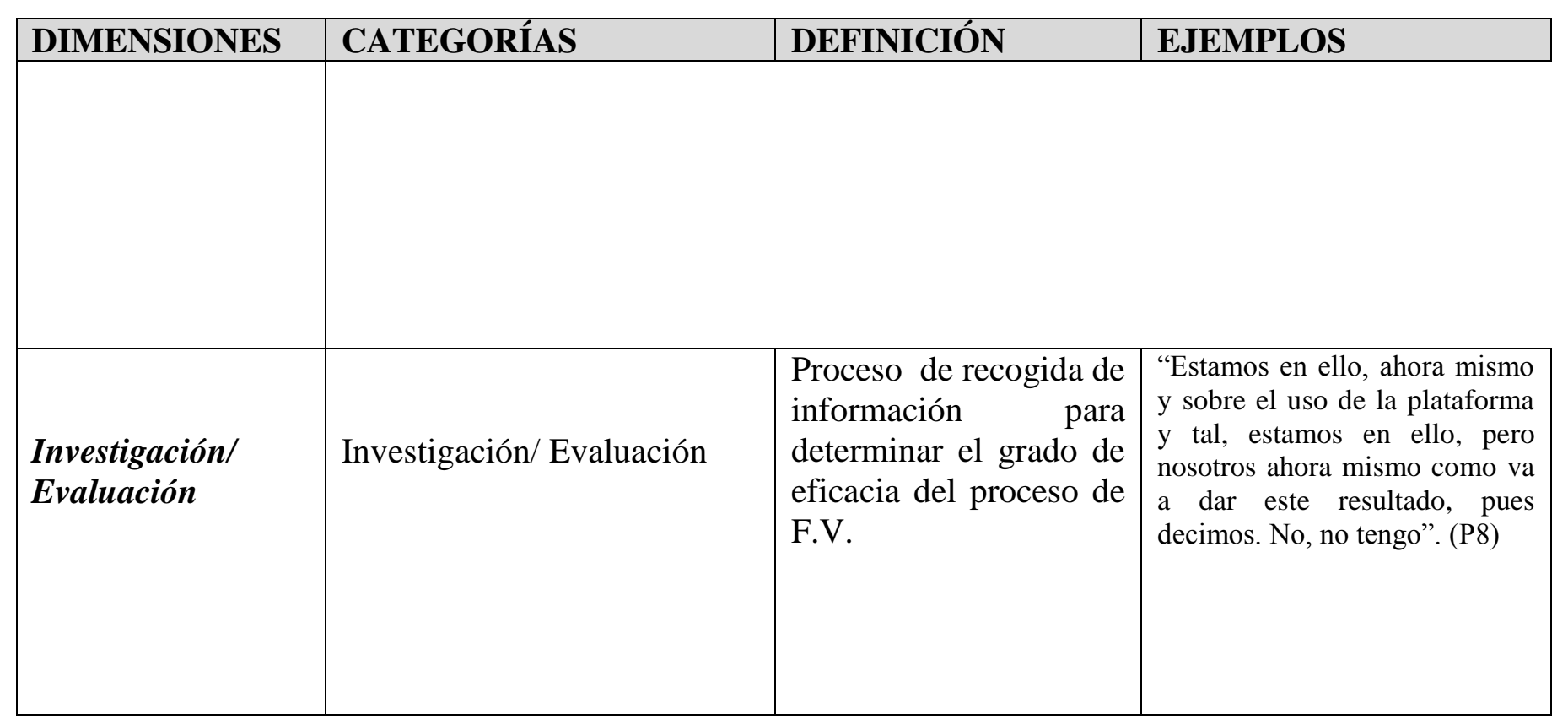

Tabla n ${ }^{\circ} 1$. Sistema Categorial.

Una vez conseguido el grado de acuerdo entre los codificadores, se pasó a la codificación de todas y cada una de las entrevistas de forma individual para efectuar posteriormente la triangulación. Para su realización se hicieron varias reuniones en las que se pusieron en común y/o discutieron las diferentes unidades de significado que cada codificador había encontrado (según Sistema de Categorías) previamente, y tras el debate se establecieron los códigos definitivos.

C) Codificación y análisis

Llegado este momento fueron repartidas las entrevistas entre los diferentes codificadores.

Una vez transcritas las entrevistas utilizamos como herramienta de ayuda para nuestro análisis el programa Atlas-ti 5.0 (Muños Justicia, 2003).

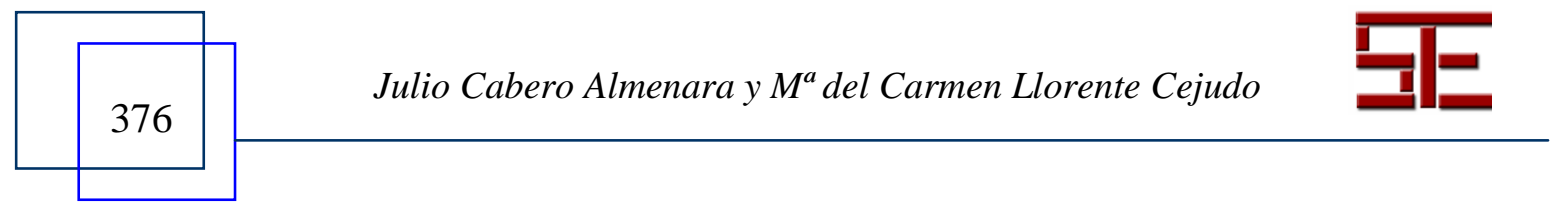




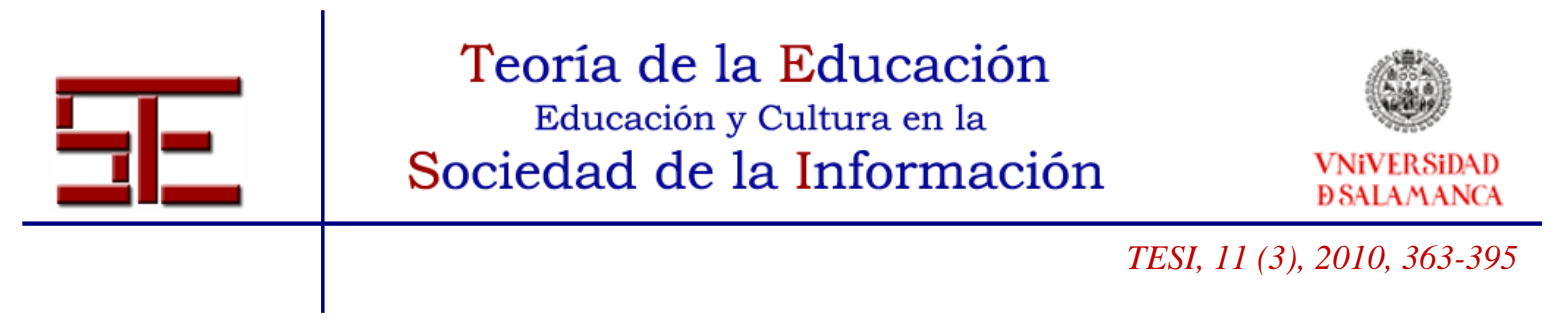

\section{6.- RESULTADOS ALCANZADOS.}

En primer lugar, vamos a presentar las frecuencias y porcentajes obtenidos en cada una de las dimensiones y categorías que conformaban nuestro Sistema Categorial, las cuales presentamos en la Tabla $\mathrm{n}^{\circ} 2$.

\begin{tabular}{|c|c|c|c|c|c|}
\hline DIMENSIONES & CATEGORÍAS & F.C & F.D & PD & $\mathbf{P C}$ \\
\hline Instituciones & Institución & 5 & 5 & & 100 \\
\hline Tiempo & Tiempo & 11 & 11 & & 100 \\
\hline \multirow{6}{*}{$\begin{array}{l}\text { Desarrollo de la } \\
\text { Formación } \\
\text { Virtual. }\end{array}$} & Motivos & 3 & \multirow[t]{6}{*}{93} & \multirow[t]{6}{*}{30,4} & 3,3 \\
\hline & Responsables de la formación & 11 & & & 12,2 \\
\hline & Apoyo empresa externa & 13 & & & 14,4 \\
\hline & Apoyo institucional & 20 & & & 22,2 \\
\hline & Plataforma utilizada & 17 & & & 18,9 \\
\hline & Porcentaje de asignaturas & 6 & & & 6,7 \\
\hline \multirow{4}{*}{ Resultados } & Problemas técnicos & 8 & \multirow[t]{4}{*}{18} & \multirow[t]{4}{*}{6,08} & 44,4 \\
\hline & Problemas didácticos & 1 & & & 5,6 \\
\hline & Problemas diseño & 2 & & & 11,1 \\
\hline & Resultados positivos técnicos & 7 & & & 38,9 \\
\hline \multirow{6}{*}{ Profesorado } & Problemas en su implantación & 13 & \multirow[t]{6}{*}{101} & \multirow[t]{6}{*}{34,1} & 12,9 \\
\hline & Formación del profesorado & 32 & & & 31,7 \\
\hline & Aceptación del profesorado & 26 & & & 25,7 \\
\hline & Incentivos & 14 & & & 13,9 \\
\hline & Información profesores & 9 & & & 8,9 \\
\hline & Capacidad del profesorado & 7 & & & 6,9 \\
\hline Alumnos & Aceptación del alumno & 10 & 15 & 1,68 & 66,7 \\
\hline
\end{tabular}

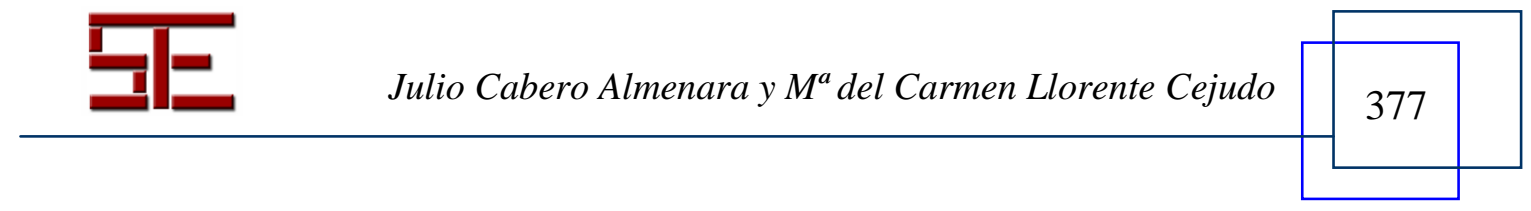




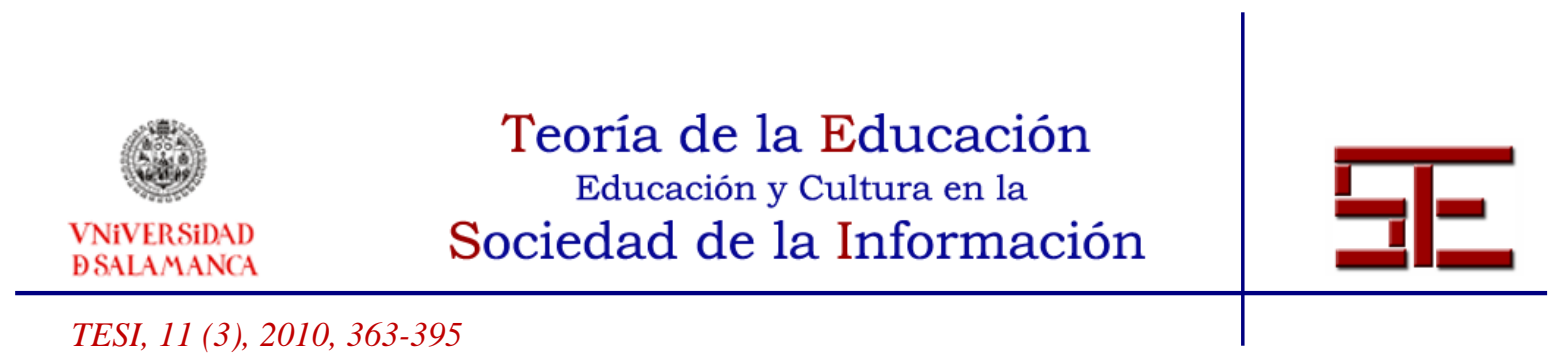

\begin{tabular}{|l|l|l|l|l|l|}
\hline DIMENSIONES & CATEGORÍAS & F.C & F.D & PD & PC \\
\hline & Información alumno & 5 & & 3,7 & 33,3 \\
\hline \multirow{2}{*}{ Buenas prácticas } & Buenas prácticas & 17 & 24 & 8,1 & 70,8 \\
\cline { 2 - 3 } \cline { 6 - 7 } & Criterios/ Requisitos & 7 & & & 29,2 \\
\hline $\begin{array}{l}\text { Investigación/ } \\
\text { Evaluación }\end{array}$ & Investigación/ Evaluación & 2 & 2 & 0,67 & 100 \\
\hline
\end{tabular}

Tabla $n^{\circ}$ 2. Frecuencia de aparición de cada una de las categorías.

Como podemos observar en la tabla $\mathrm{n}^{\circ}$ 2, la dimensión que obtuvo mayor porcentaje fue "Profesorado" (34.1\%), seguida de "Desarrollo de la formación virtual" (30.4\%) y, a bastante más distancia, el resto de dimensiones: "Buenas prácticas" $(8.1 \%)$, "Resultados" (6.08\%), "Alumnos" (5.06\%), "Tiempo" (3.7\%), "Instituciones" (1.68\%) e "Investigación/Evaluación" (0.67\%). Ello ya nos sugería las direcciones hacia las que iban encaminadas las preocupaciones fundamentales de los entrevistados.

En la Figura $n^{\circ} 1$ podemos observar, con más claridad, los porcentajes obtenidos en las diferentes dimensiones.

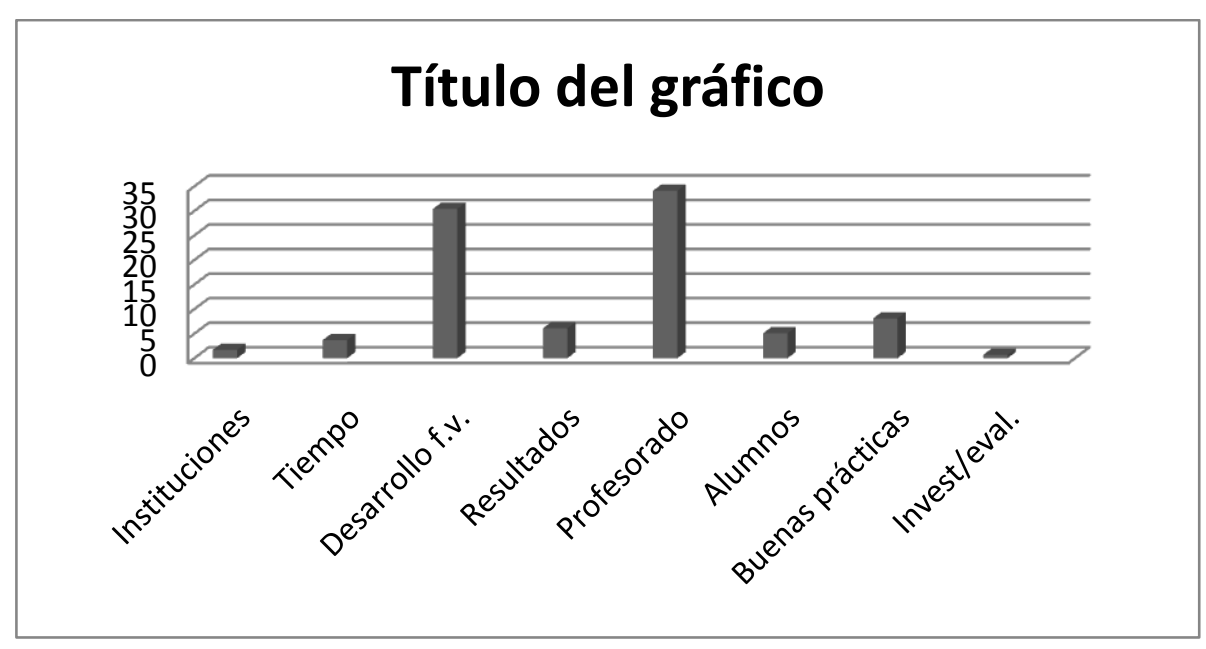

Figura $n^{\circ} 1$. Representación gráfica de los porcentajes obtenidos en las diferentes dimensiones y categorías.

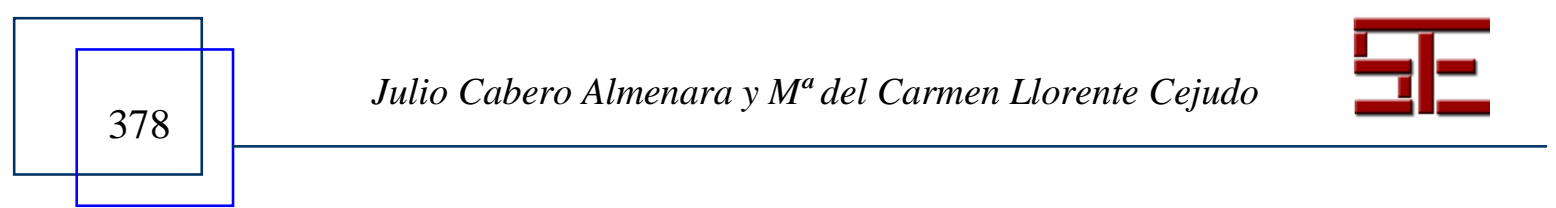




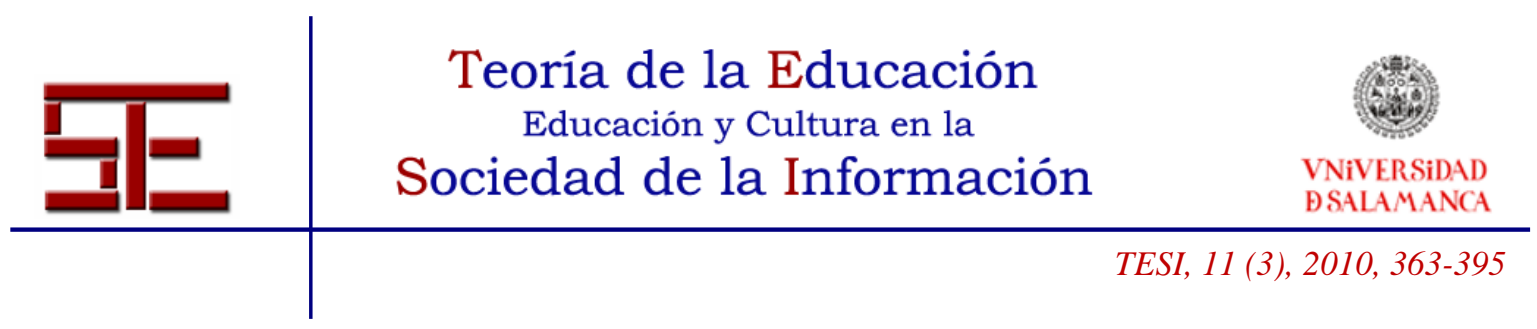

Una lectura rápida nos permitía conformar tres grandes grupos de intereses en las dimensiones por parte de los entrevistados: a) Profesorado y desarrollo de la formación virtual, b) Tiempo, resultados, alumnos y buenas prácticas, y c) Instituciones, e investigación y evaluación.

A priori, no parecía extraña la diferencia de porcentajes obtenidos por las diferentes dimensiones, teniendo en cuenta que las entrevistas fueron realizadas a responsables técnicos del campus virtual en sus respectivas universidades. Nos encontramos con unos profesionales preocupados por el desarrollo técnico del proceso, así como por los agentes con los cuales más directamente tenían que trabajar para llevar a cabo el proyecto, es decir, el profesorado. Y ello lo pudimos percibir también desde otra perspectiva, ya que fueron dimensiones que aparecieron en casi todas las entrevistas realizadas.

En la segunda línea de preocupación, aparecían las referencias al tiempo, a la adquisición de resultados y a los otros actores implicados en el proceso: los alumnos.

A continuación, y siguiendo el orden que hemos descrito anteriormente, iremos comentando cada una de las dimensiones. Pero antes de comenzar el análisis, señalar dos aspectos: uno, que solamente dos entrevistados hicieron referencias de todas las categorías que habíamos propuesto para el análisis de la presente dimensión, y dos, que no todas las categorías se dieron en todas las entrevistas. En concreto, la de problemas de implantación no apareció en seis entrevistas, la de formación del profesorado en tres, la de aceptación del profesorado en cuatro, la de incentivos en cuatro, la de información de profesores en seis y la de capacidad del profesorado en ocho.

Comenzando nuestro análisis de la dimensión con un mayor porcentaje, profesorado ( $\mathrm{f}=101,34,1 \%$ ), la categoría que obtuvo una mayor representación en la misma fue la de formación del profesorado $(\mathrm{f}=32,31,7 \%$ ). Con esta categoría quisimos recoger las manifestaciones realizadas por los entrevistados, relativas al esfuerzo efectuado por las diferentes universidades en formar al profesorado en el uso de las TIC en general, y las referidas a la formación virtual en particular. A la luz de lo comentado por los responsables técnicos entrevistados nos encontramos ante un aspecto muy tenido en cuenta por las diferentes universidades. Todas tenían un servicio de apoyo al profesorado al cual todos podían acceder para consultar cualquier duda que le asaltase en el proceso de incorporación de la formación virtual.

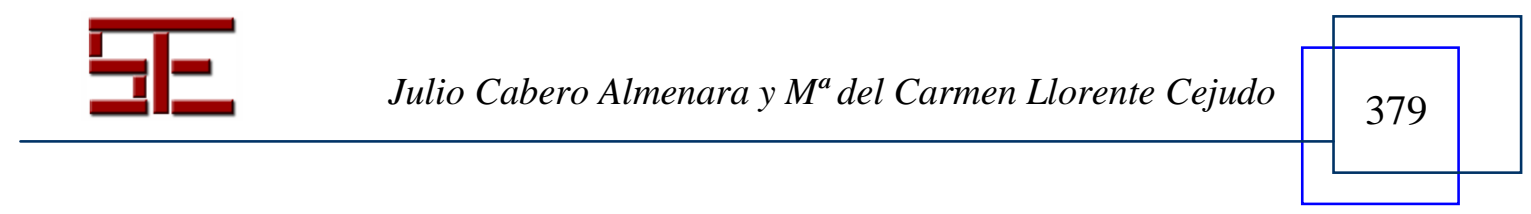




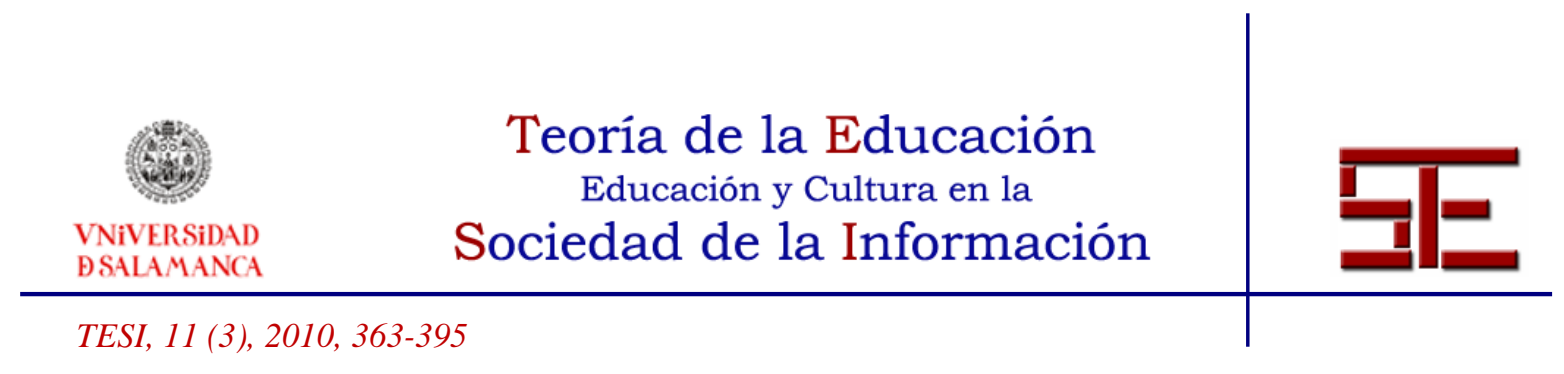

...sobre todo nosotros hemos basado mucha formación y mucho entrenamiento más que en distribuir material, en tener un grupo de gente, un grupo de personas permanentemente en el teléfono pendiente, y en el correo electrónico claro, pendiente de los problemas. (ENTRE06.rtf - 6:17)

Igualmente, la mayoría de las universidades materializaron estos procesos de formación en planes de entrenamiento y capacitación.

...tenemos un servicio de apoyo, que en la mayoría de los casos, ehh, se hace mediante un plan de formación estructural que se ofrece al profesorado, que el profesorado, ehh, solicita de ese plan de formación lo que a él más le interesa.(ENTRE02.rtf - 2:7)

La siguiente categoría de la dimensión "Profesorado" en orden decreciente de aparición fue "Aceptación del profesorado" ( $f=26,25,7 \%)$. Con esta categoría recogimos todas aquellas manifestaciones de los entrevistados que hacían referencia a la actitud y el interés del profesorado ante la incorporación de la formación virtual.

Podemos decir que el mejor indicador del e-learning fue el gran nivel de aceptación entre los profesores de las distintas universidades implicadas en el estudio, el número de asignaturas -y por lo tanto, de profesores inmersos en el proceso- que iban en constante aumento de un curso a otro.

...con respecto a los indicadores que tenemos ésta a seguido una evolución bastante buena, cada año tenemos más asignaturas colgadas en campus virtual $y$ de profesores que utiliza la plataforma. (ENTRE05.rtf - 5:3)

Al mismo tiempo, los entrevistados percibían que el profesorado veía sentido a este tipo de herramientas, viéndola como un recurso fundamental para el desempeño de su docencia en los momentos históricos en los cuales nos desenvolvemos.

...nuestra impresión y los datos que tenemos son muy positivos en el aspecto de que están muy interesados y cada vez vemos más gente que se implica en la enseñanza virtual no porque esté de moda, no porque le den puntos, sino porque lo están viendo como una herramienta fundamental para su docencia.... (ENTRE01.rtf - 1:28)

Aunque también, según lo comentado por los entrevistados, nos encontramos con profesores que se veían superados por el proceso, o este no es lo que esperaban, y se sentían agobiados y abandonaban.

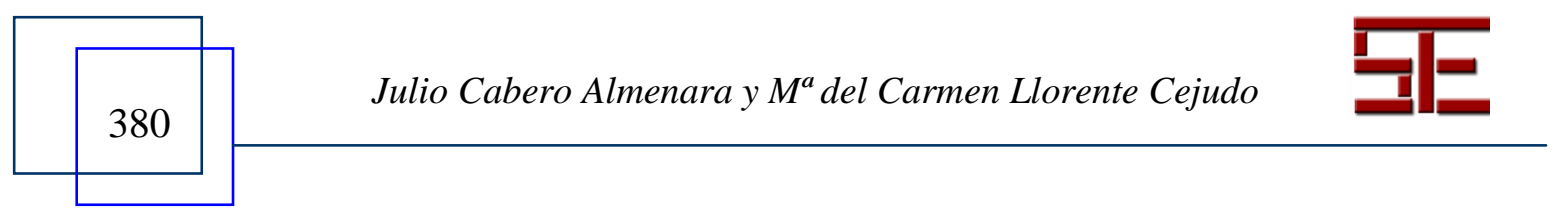




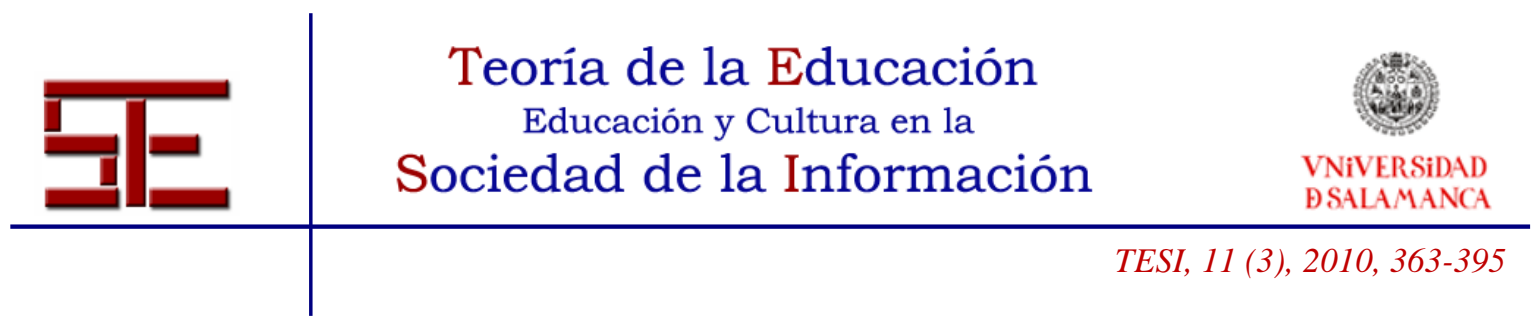

...si, está el otro que se agobia, que dicen que le llegan 30 correos el sábado por la mañana y que está todo el día enganchado en eso, pero que le supera, le agobia y que no quiere saber más de la enseñanza virtual.... (ENTRE01.rtf $1: 30)$

Pero, en general, podemos concluir diciendo que el profesorado estaba respondiendo bien, y nos manifestaron que se encontraban contentos con el desarrollo de la formación virtual en sus Universidades.

...la gente está respondiendo muy bien .... (ENTRE06.rtf - 6:20)

Con la categoría "Incentivos" ( $\mathrm{f}=14,13,9 \%)$ se recogieron aquellas manifestaciones de los entrevistados en las que nos hablaban de la ayuda que recibía el profesor para motivarlo o estimularlo a incorporarse al proceso de formación virtual. Podemos decir que estos incentivos variaban de unas universidades a otras, unas entendían que el docente debía sentirse suficientemente incentivado por poner a su disposición esta herramienta, ya que ésta es entendida como una ayuda, no como un incentivo:

...no, en principio lo que se le ofrece es la herramienta como ayuda no un incentivo.... (ENTRE01.rtf - 1:32)

Pero en otros casos, la recompensa era académica:

...y sobre todo, bueno recompensa académica, no ha habido recompensa económica.... (ENTRE06.rtf - 6:13)

Y otras veces el profesor recibía hardware y software necesario para su docencia,

...una webcam y unos auriculares con micrófono, ehh, para que no se sienta falto de recursos en ese sentido. Además de todo el software que requiere.... (ENTRE07.rtf - 7:32)

Es de señalar que una de las actividades que se estaba llevando a cabo en diferentes universidades fue la entrega a todos los profesores participantes en procesos de enseñanza-aprendizaje en entornos virtuales de un ordenador portátil.

...se les da un portátil, y si hay un software especial que ellos necesiten utilizar, se valora y se ve si compra o no una licencia personal si va a ser algo muy aislado, que solamente lo utilicen ellos.... (ENTRE06.rtf - 6:20).

En cuanto a los "Problemas en su implantación" ( $\mathrm{f}=13,12,9 \%)$, nos encontramos con que el primer problema por el que mostraron una preocupación los entrevistados, fue el superar la desorientación del profesorado en estos menesteres. Lo cual, en cierta

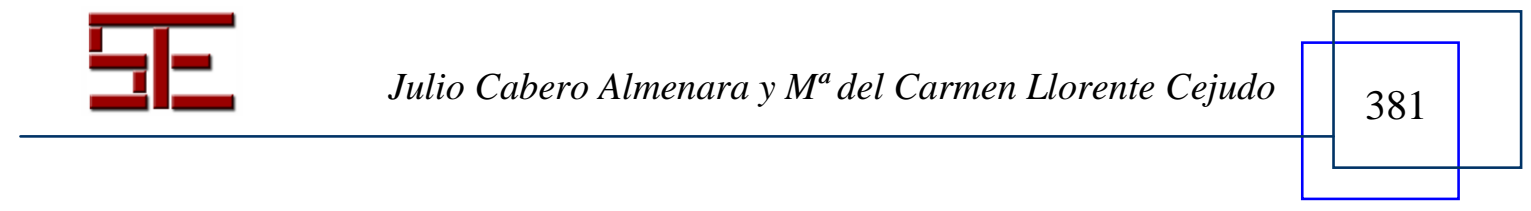




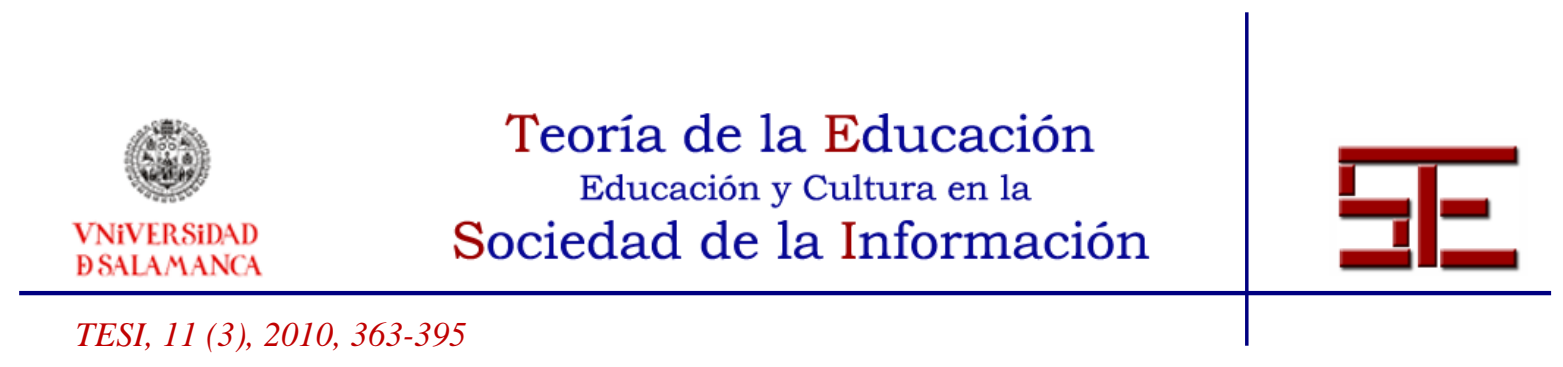

medida, era lógico puesto que suponía nuevas formas de enfrentarse al acto sémicodidáctico de la enseñanza.

...los profesores en un principio estaban un poco perdidos de cómo tenía que ser la docencia no presencial.... (ENTRE06.rtf - 6:20)

Una vez superado este primer escollo, básicamente las instituciones manifestaban encontrarse con dos obstáculos a nivel del profesorado. Por un lado, con los profesores que no participaban y que no sabían cómo llegar a ellos o como motivarlos para que hiciesen un uso de estas herramientas:

...hay gente que no tiene su asignatura en campus virtual, son gente que no participa y que no opinan y que no sabemos cómo llegará a ellos (ENTRE01.rtf $-1: 29)$

En quinta posición, nos encontramos con la categoría "Información profesores" ( $f=9,8,9 \%$ ). Con ella pretendimos recoger las aportaciones de los entrevistados, relacionada con la elaboración de materiales para apoyar-orientar al profesor en el proceso de la formación virtual. A partir de las manifestaciones de los entrevistados podemos decir que en las instituciones en las que desarrollaban su actividad se contempló necesaria la existencia de esos manuales, que en definitiva, ayudaban a la tarea docente.

“...hay unos materiales editados por el servicio de informática que se distribuyen a todos los participantes en el curso y tienen una versión del curso también on-line para usar la plataforma.". (ENTRE011.rtf - 11:22)

“...sobre el funcionamiento de la plataforma y cómo preparar el material, vamos cómo adaptarlo." (ENTRE 12.rtf-12:10)

La última de las categorías en orden decreciente de porcentaje fue la de "Capacidad del profesorado" ( $\mathrm{f}=7,6,9 \%)$. En esta línea, los entrevistados nos señalaban que se encontraban ante todo tipo de docentes, desde los que tenían alguna o mucha idea y para ellos este tipo de herramientas era positivo para el desarrollo de actividades docentes, hasta los que mostraban un desconocimiento total.

“...tenemos de todo, desde profesores que están como muy acostumbrados al tema y la utilizan, a profesores que es que prácticamente no saben moverse, no ya dentro de la plataforma sino incluso en el propio ordenador." (ENTRE012.rtf - 12:3).

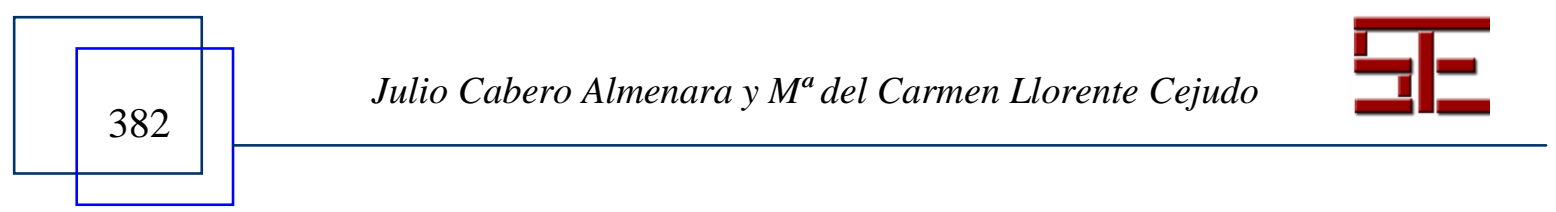




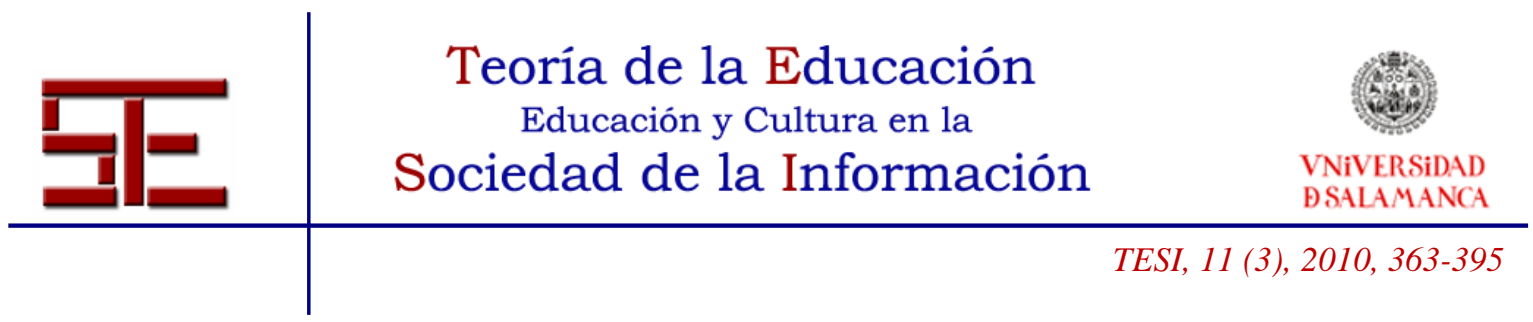

La siguiente de las dimensiones en orden decreciente de frecuencia y porcentajes de las competencias que forman parte de ella con que nos encontramos en nuestro estudio fue la de "Desarrollo de la formación virtual" ( $\mathrm{f}=93,30,4 \%)$.

En esta dimensión, y de acuerdo a las frecuencias alcanzadas, podemos establecer la siguiente ordenación en las diferentes categorías que la componían: 1) Planificación Apoyo institucional, 2) Plataforma utilizada, 3) Apoyo empresa externa, 4) Responsables de la formación, 5) Porcentaje de asignaturas, y 6) Motivos.

La categoría con mayor frecuencia de aparición en esta dimensión fue la de "Apoyo institucional" ( $\mathrm{f}=20,22,2 \%)$. Con ella se pretendió recoger las manifestaciones relacionadas con la información que sobre el apoyo se han llevado a cabo desde la propia institución en el desarrollo del proceso de formación virtual. Básicamente, para ofrecer este apoyo al profesorado, se utilizaron diferentes modalidades por parte de las universidades, aunque sí que podemos decir que en todas ellas se ponía a disposición del profesorado que lo desease un servicio de apoyo permanente.

...hemos puesto en marcha una labor de tutorías telefónicas, hemos abierto un servicio de consultoría, de gestión de contenido, en la escuela hay cinco personas contestando las dudas sobre unas cuarenta herramientas de gestión d contenidos. (ENTRE06.rtf - 6:11)

Apoyo que, además, era demandado por los docentes:

A menos que algún profesor nos pida una ayuda en eso, y que entonces si se les asesora en el diseño de los contenidos o en como pasar, que te digo yo, un video que tiene en DVD pues pasarlo a un video digital para colgarlo en el campus. (ENTRE01.rtf - 1:21)

...el profesor quiere virtualizar una asignatura, rellena un formulario y una solicitud con la ayuda del becario correspondiente de cada centro y una vez lo haga, pues ya nosotros le decimos cuál es su nombre de usuario, su contraseña, cómo tiene que acceder... (ENTRE07.rtf - 7:11).

Con la misma frecuencia y porcentaje que la categoría anterior, nos encontramos con "Planificación", categoría con la que se recogían las manifestaciones de los encuestados relacionados con el conjunto de pasos que se establecían para el desarrollo del proceso de formación virtual. La planificación del proceso, en la mayoría de los casos, partió de la puesta a disposición de cursos de formación que posteriormente eran evaluados con la intención de mejorar el proceso.

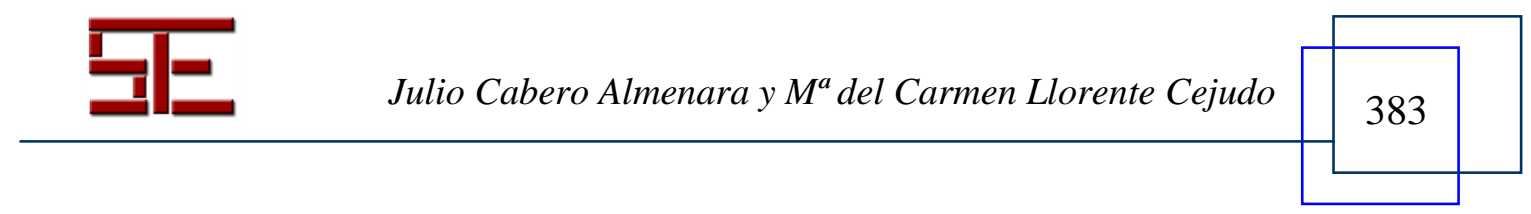




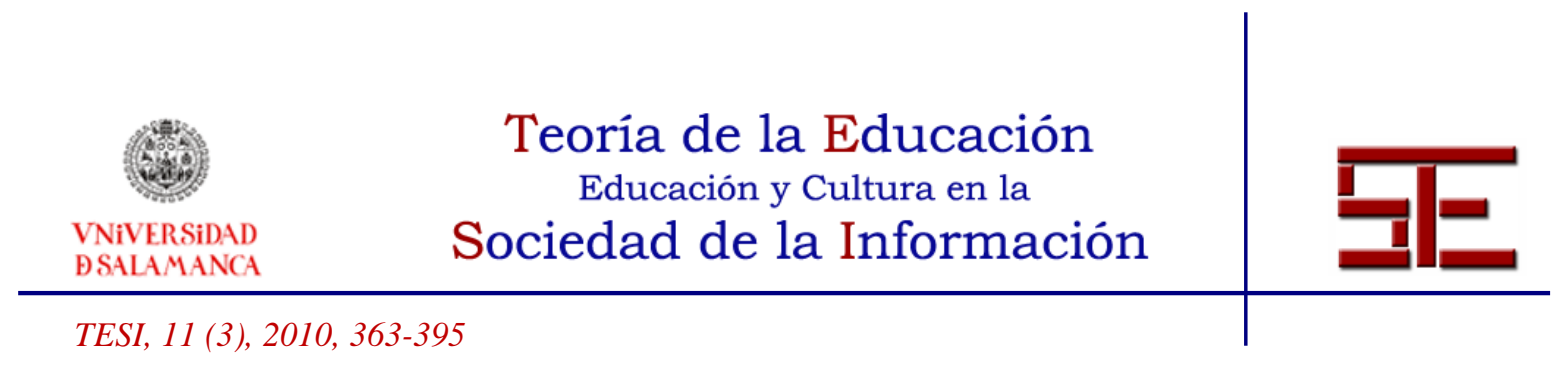

Una, se hacen convocatorias de cursos, que se diseñan desde aquí, intentamos diseñar, bueno pues siguiendo distintos datos y distintas informaciones que tenemos. Se les hacen encuestas a los participantes después de los cursos para ver qué les ha parecido y ver lo que necesitan y de esta forma generamos un plan de formación. (ENTRE01.rtf - 1:5).

Igualmente se planificaban los planes de formación a partir de peticiones del profesorado realizados en convocatorias abiertas.

...hay una convocatoria abierta para grupos, para seminarios permanentes, para departamentos, para grupos de profesores que quieran y piden una formación en centros. (ENTRE01.rtf - 1:9).

En la categoría "Plataforma utilizada" ( $\mathrm{f}=17,18,9 \%$ ), se recogieron las manifestaciones realizadas respecto a la plataforma utilizada en el proceso de formación virtual y puesta a su disposición por la Universidad. En relación a este elemento, decir que básicamente las universidades participantes en el estudio utilizaban las plataformas Moodle o WebCT (una de código libre y otra propietario).

...Moodle es una plataforma, da pocos problemas y los profesores se adaptan bien. (ENTRE07.rtf - 7:24)

...WebCT en principio, es un software privativo, una plataforma, muy extendida y proporcionaba un interfaz bastante amigable para el profesor, un a primera solución y yo creo que esa fue la decisión. (ENTRE07.rtf - 7:25)

Estas tres categorías conformaban cerca del $60 \%$ de las participaciones del profesorado en esta dimensión y, por tanto, el gran peso que las mismas tenían para los entrevistados en que la implantación de la formación virtual pudiese ser de manera exitosa. En definitiva, el apoyo institucional, la planificación de la acción y la plataforma.

Para recoger información relativa a la existencia de apoyo externo en el desarrollo del proceso de formación virtual utilizamos la categoría "Apoyo empresa externa" ( $\mathrm{f}=13$, $4,4 \%$ ), pues una serie de entrevistados nos hicieron referencia que en su Universidad existía un personal no vinculado a la Universidad. Sí nos pareció llamativo, gracias a los comentarios de los encuestados, que todas las universidades que usaban la plataforma WebCT tenían contratado un servicio con la empresa Sadiel.

...sobre WebCT aquí en Andalucía, todas las universidades que tengan WebCT implantado, parte de, es siempre Sadiel. (ENTRE07.rtf - 7:28).

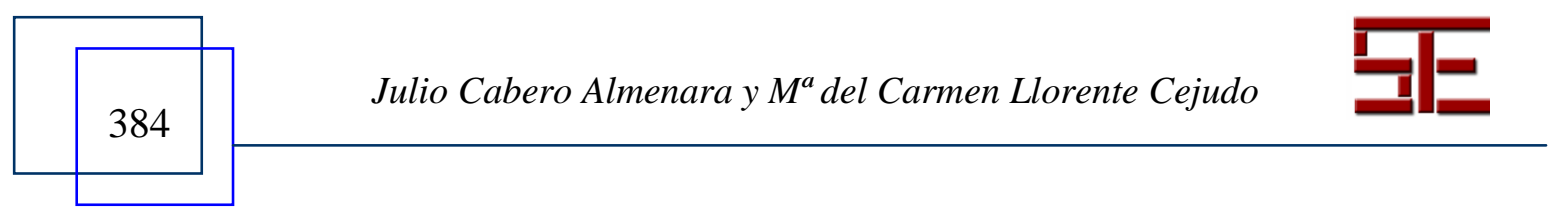




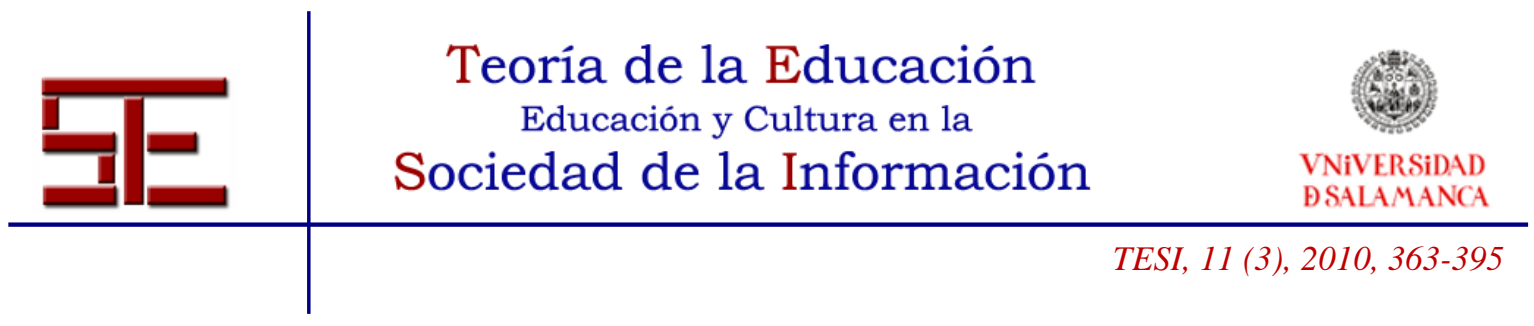

Por su parte, las universidades que utilizaban software libre tendían a que fuesen sus propios servicios los que se encargaran de todo el proceso de elaboración de contenidos y apoyo al profesorado.

...no, no, lo llevamos nosotros... (ENTRE01.rtf - 1:13).

Con la categoría "Responsable de la formación" ( $\mathrm{f}=11,12,2 \%)$, se recogieron manifestaciones de los encuestados relativas a la persona o institución responsable del proceso de F.V. en las respectivas universidades de los encuestados. Según los comentarios de los entrevistados, podemos decir que en la mayoría de las universidades existían servicios de apoyo, personalizados en los responsables de implantación del proceso de enseñanza virtual.

Servicio de apoyo en tecnología, donde cualquier cosa relacionada con los servicios tecnológicos que ofrece la universidad, tecnológico en el sentido de TICs, por ejemplo, manejo de plataformas en docencia virtual, elaboración de materiales, módulos de aprendizaje... (ENTRE09.rtf - 9:37).

De todas formas, también nos encontramos con manifestaciones que hacían referencia a que los responsables se encontraban en los diferentes centros universitarios.

...el responsable de cada centro. (ENTRE07.rtf - 7:39).

O los encargados de enseñanza virtual.

Normalmente son los encargados de enseñanza virtual, los que están trabajando allí. (ENTRE08.rtf - 8:6)

Para recoger las manifestaciones de los encuestados relacionadas con el número de asignaturas implicadas en el proceso, utilizamos la categoría "Porcentaje de asignaturas" ( $f=6,6,7 \%)$. Y en este aspecto, independientemente del volumen existente en cada una de las universidades andaluzas, lo que si nos pareció significativo destacar era que el número de asignaturas creció a gran velocidad en todas ellas:

... a finales del 2006 existian 60 asignaturas en un CD, ahora ya estamos trabajando después de dos años con cerca de 1200 asignaturas... (ENTRE04.rtf $-4: 2)$

La última de las categorías de esta dimensión es la categoría "Motivos" ( $\mathrm{f}=3, \%=3,3$ ). Categoría respecto a la cual tenemos que señalar, en primer lugar, que apareció con una frecuencia muy baja, y que con ella se recogían las manifestaciones que realizaron los entrevistados que estaban relacionadas con las motivaciones para la puesta en funcionamiento del proceso de F.V. Básicamente, la motivación de las instituciones

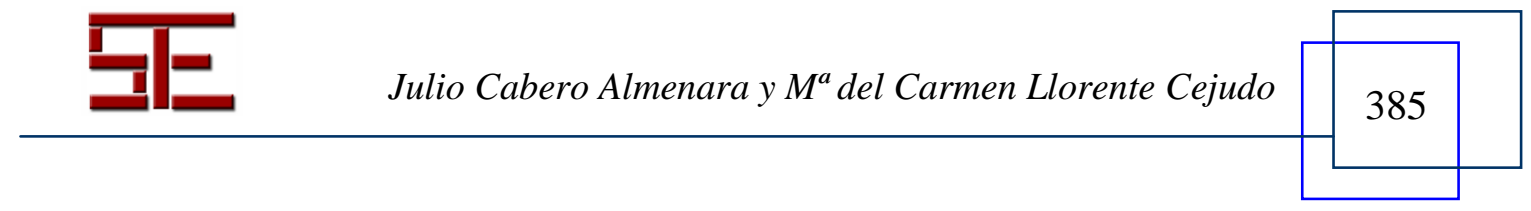




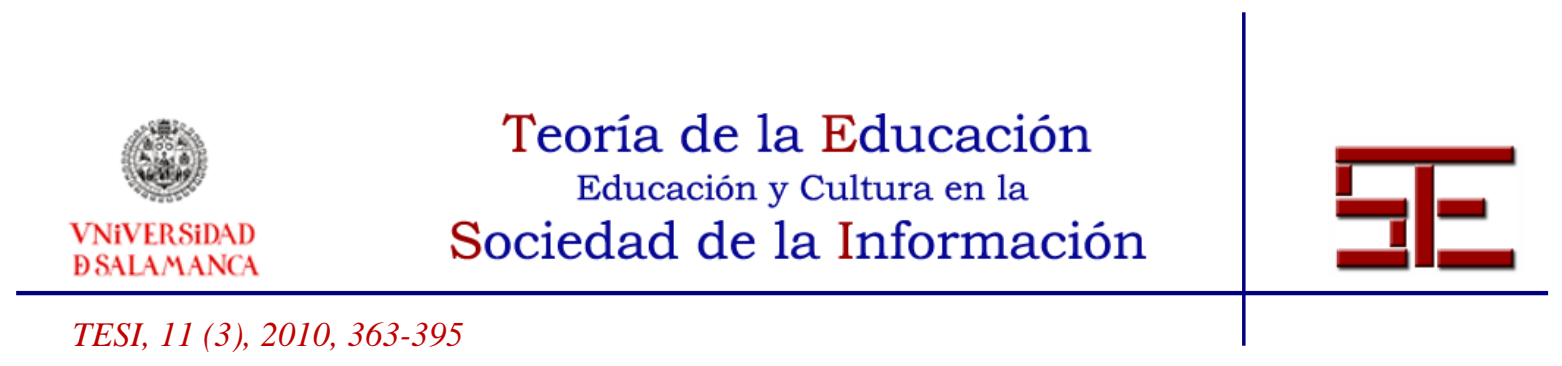

para poner en marcha estos procesos era que las acciones de teleformación constituyen uno de los pilares y objetivos de prioridad de todas ellas.

...dentro del plan de formación pues entra uno de los pilares del plan de formación, solamente uno, pero son cuatro los grandes campos, pero uno de ellos es la teleformación. (ENTRE08.rtf - 8:2)

La siguiente dimensión en orden decreciente fue "Buenas prácticas". Lo primero que tenemos que señalar es que tampoco en este caso se dio una utilización de todas las categorías por los entrevistados, ni la presentación de las categorías en todas las entrevistas realizadas.

A la luz de lo comentado por los entrevistados, parece que sí existían trabajos realizados por profesores o grupos de profesores que destacaban sobre los demás y que podían facilitar el desarrollo de actividades de aprendizaje en las que se lograsen con eficiencia los objetivos formativos previstos y también otros aprendizajes de alto valor educativo. Estos registros los codificamos bajo la categoría "Buenas prácticas" ( $\mathrm{f}=17,70.8 \%)$.

...hay asignaturas y profesores que se distinguen por, por innovar o porque trabajan más cerca y más centrado en el trabajo del alumno ¿no?, o sea más cerca de sus alumnos, más, y que al final si es cierto que parecen provocar por lo menos más dinamismo y mas... (ENTRE01.rtf - 1:26).

En esta línea destacan las asignaturas incluidas en el campus virtual andaluz, con la peculiaridad de que son totalmente virtuales.

...tú sabes que existe un campo entero virtual en el que hay 10 universidades de Andalucía que imparten sus asignaturas de forma virtual. Yo quizás quería destacar esas asignaturas, porque claro, al ser virtuales pues, hay que montarlo de una forma quizás mejor que las asignaturas que son presenciales. (ENTRE05.rtf - 5:10).

Con menos de la mitad de frecuencias de aparición, nos encontrábamos con la categoría "Criterios/Requisitos" ( $\mathrm{f}=7,29,2 \%)$, donde se recogían todas aquellas manifestaciones efectuadas en las que se nos comentaba algo sobre las condiciones necesarias para formar parte del proceso de formación virtual.

...cuando damos el apoyo técnico, procuramos que esté todo lo que debe estar según este documento. Digamos, se diseñan las cosas en función de unas indicaciones que recogen una serie de bases para el diseño de materiales didácticos en red aparte de un aserie de indicaciones puramente técnicas y de

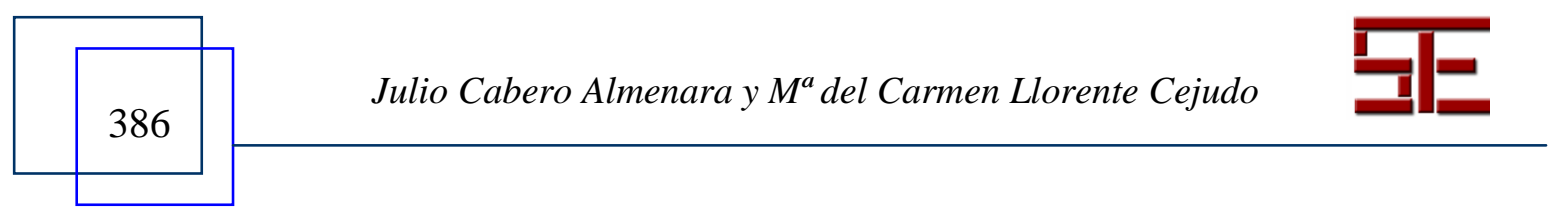




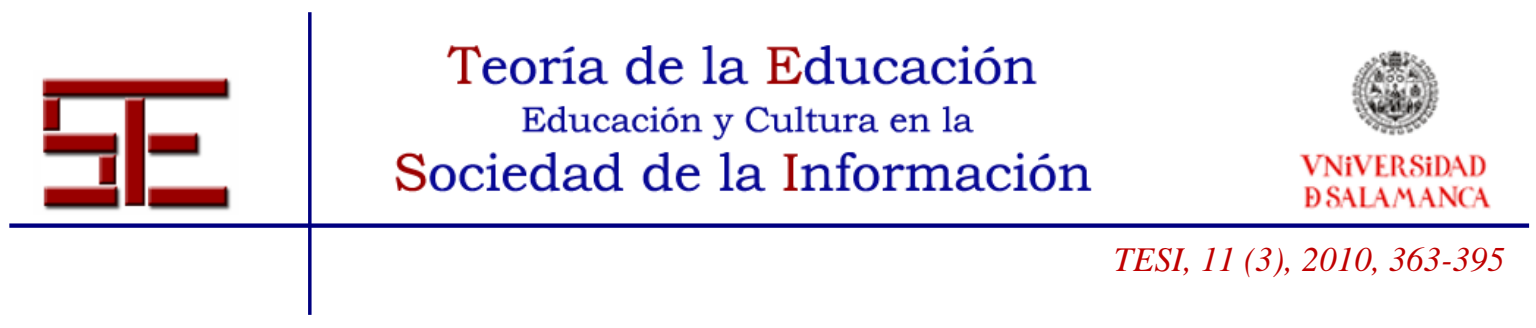

diseño gráfico y a la vez las propias necesidades del profesor. (ENTRE11.rtf11:8).

Al final las asignaturas debían tener una serie de características:

"Estas asignaturas pues tienen que tener estas características no, pues... que tenga una red de contenidos, unos recursos de profundización, una representación, un mapa conceptual, que después, durante, por la navegación el alumno sepa siempre donde está." (ENTRE11.rtf - 11:5).

En cuarto lugar, por orden decreciente de frecuencia de aparición, nos encontramos con la dimensión "Resultados". La aparición de referencias relativas a estas categorías fue dispar, encontrándonos con dos: "Problemas técnicos" ( $\mathrm{f}=8,44,4 \%)$ y "Resultados positivos técnicos" ( $\mathrm{f}=7,38,9 \%$ ), que aglutinaban el mayor número de apariciones, mientras que de las otras dos: "Problemas diseño" ( $f=2,11,1 \%$ ) y "Problemas didácticos" ( $\mathrm{f}=1,5,6 \%)$, apenas aparecían con referencias al compararlas con las otras. Tal diferencia nos indicaba, al mismo tiempo, la significación que le concedieron nuestros entrevistados.

Con la categoría "Problemas técnicos" pretendimos recoger las manifestaciones que realizaron los entrevistados relacionadas con problemas que de tipo técnico pudieron surgirles durante el proceso de desarrollo de la implantación de la formación virtual en su universidad. Entre estos problemas, a uno de los que le concedían mayor importancia era el de la conectividad, aunque tenemos que señalar que progresivamente la misma se fue solucionando, ya que cada vez ésta iba siendo más amplia.

Al principio hace cinco pues lo que es la conectividad de los alumnos en su casa o lo que es en un piso de alquiler pues estaba muy limitada... (ENTRE09.rtf 9:26).

Otro tipo de problemas que se solían dar eran los de infraestructura, que también se fueron solucionando.

...en principio si ha habido alguno son ya muy ligados a lo que es... no sé cómo te diría a la infraestructura a la que accede el profesor o el alumno, pero muy bajo. (ENTRE10.rtf - 10:9).

La siguiente categoría era "Resultados positivos técnicos", donde se recogieron las manifestaciones relacionadas con los resultados obtenidos por los procesos de implantación de la F.V. Podemos decir, a la luz de los comentarios, que los resultados obtenidos eran bastante buenos, como ejemplo uno de los comentarios de los entrevistados.

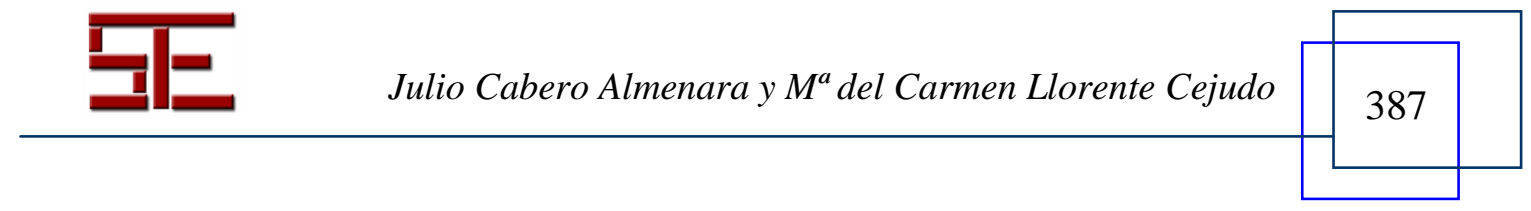




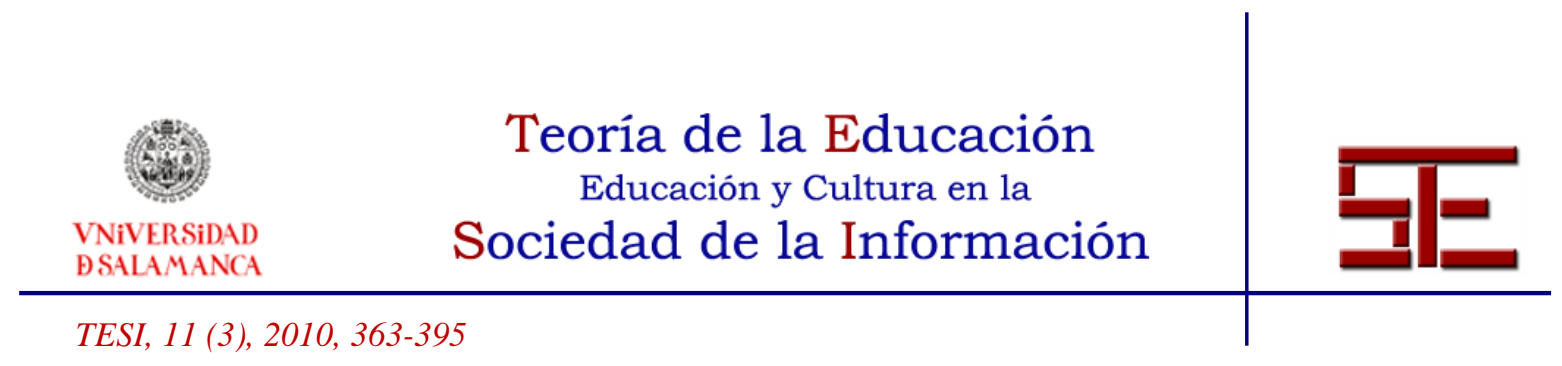

Este año podemos llegar fácilmente al 70\% de las asignaturas y al 100\% de los alumnos con presencia virtual y la gente está contenta (ENTRE06.rtf - 6:4)

Otro ejemplo de la importancia que iban adquiriendo estos menesteres, es que los secretariados encargados de llevar a cabo el mantenimiento de esta F.V eran los que mayor peso estaban adquiriendo dentro de las universidades.

Hombre, el despliegue técnico ha sido importante, estuvimos trabajando tantos usuarios que ahora mismo es uno de los, es el sistema informático que tiene más carga de la universidad porque la utilización es de 24 horas al día. (ENTRE09.rtf - 9:17).

Como hemos comentado anteriormente, con mucha menos presencia, nos encontramos con la categoría "Problemas de diseño", con la que recogimos las manifestaciones de los encuestados relativas a dificultades en el diseño con las que se encontraban en el proceso de implantación de la formación virtual. Básicamente, en las pocas referencias que hemos encontrado, el principal problema con el que se encontraban los técnicos era el que los profesores comprendían que había que unificar los criterios en el diseño de los materiales y no dejarse guiar por la originalidad a la hora de hacerlo.

...me cuesta bastante trabajo metérselo en la cabeza a los profesores, porque es muy típico que aprendan a personalizar los iconos y se dediquen a poner iconos, a ellos les parece estupendo pero claro, ese icono no te dice nada como icono y más si estas saltando de una asignatura a otra y cada cosa se representa de otra manera. (ENTRE11.rtf - 11:12).

Por último, y con una muy escasa representación, nos encontramos con la categoría "Problemas didácticos", con la que pretendíamos recoger las manifestaciones relacionadas con las dificultades de índole didáctico/organizativa a la que se enfrentaba el desarrollo de formación virtual.

La siguiente dimensión por frecuencia de aparición fue la de "Alumnos", que estaba formada por las categorías: "Aceptación del alumnado" e "Información alumno". En este caso, la categoría que obtuvo una mayor frecuencia de aparición es la de "Aceptación del alumno", con la que pretendíamos recoger las manifestaciones de los encuestados relacionadas con la actitud, el interés del alumno en la incorporación de la F.V. Podemos decir que la aceptación de estas modalidades de enseñanza-aprendizaje por parte de los alumnos fue total, al menos si tenemos en cuenta el número creciente de ellos que van accediendo a esta modalidad.

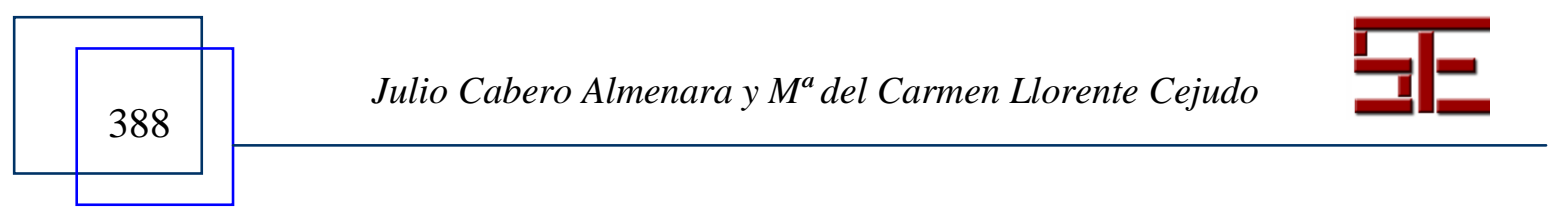




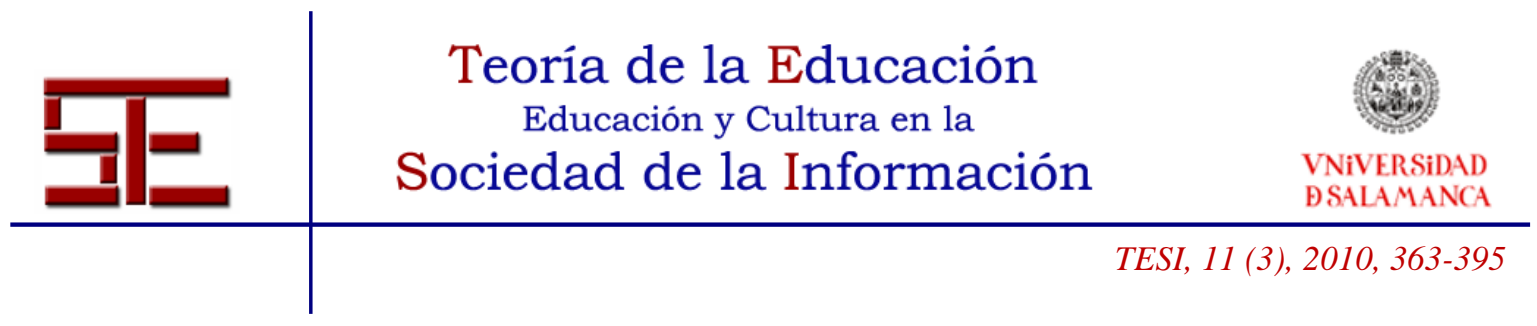

...con respecto a los indicadores que tenemos ésta ha seguido una evolución bastante buena, cada año tenemos más asignaturas colgadas en el campus virtual y se ve que cada vez aumenta más el número de alumnos, de profesores que utilizan la plataforma. (ENTRE05.rtf - 5:3).

Otro indicador es que eran los propios alumnos los que pedían a los docentes que les subieran los contenidos a la plataforma.

...los mismos alumnos les iban pidiendo a los profesores en vez de fotocopias déjamelo aquí que este me lo está dando.... (ENTRE09.rtf - 9:8).

...quien ha tirado de esto son los alumnos. Los alumnos al principio tenían una asignatura, pero se metían mucho en la plataforma, a señalar la asignatura, se destacaban y automáticamente aquellos mismos son los que le preguntan al profesor: oye y vas a poner tú los apuntes en la plataforma, o va usted a poner algún tipo de actividad en la plataforma, algún foro o algo para plantear dudas. (ENTRE09.rtf - 9:14).

En cuanto a la creación de materiales para ayudar-orientar al alumno en el proceso de la F.V., "Información alumno" ( $\mathrm{f}=5,33,3 \%$ ), tenemos que decir que por regla general, a la luz de los comentarios de los entrevistados, los alumnos no solían tener muchos problemas.

Desde el punto de vista del alumno, no estamos teniendo problemas porque es que los alumnos se manejan muy bien en ese sentido independientemente de la titulación... (ENTRE09.rtf-9:25).

Pero, independientemente de esto, en las plataformas suelen incluir un tutorial básico sobre el manejo de éstas.

El alumno, en la plataforma hayan tutorial básico sobre el manejo de la plataforma, que realmente es muy sencillo... (ENTRE09.rtf - 9:38).

Igualmente, como en el caso de los profesores, los alumnos eran atendidos en sus dudas por grupos de técnicos asignados para tal tarea.

Por ejemplo, un alumno se puede, no se puede dar de alta, pues te llega un correo y tu le describes los pasos que tiene que seguir para darse de alta. (ENTRE05.rtf - 5:1).

Para finalizar nuestro análisis, y antes de presentar las conclusiones que nos permiten obtener los valores alcanzados en las dimensiones que tenían una única categoría, es decir, "Tiempo" e "Instituciones", apuntar que por lo que respecta a la primera de ellas

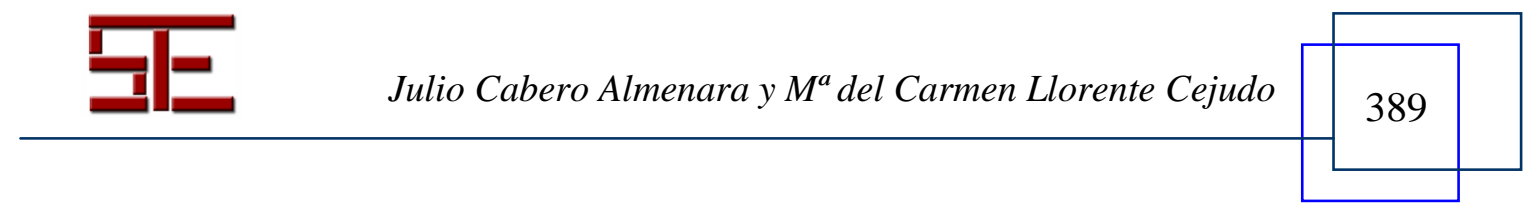




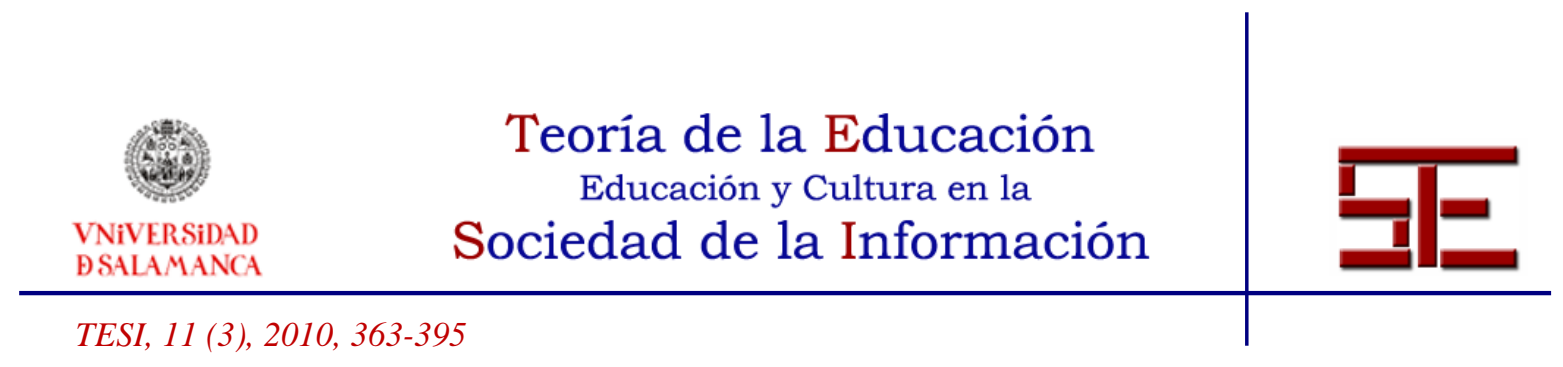

(la cual se compone de una única categoría con su mismo nombre, tiempo), tenemos que señalar que obtuvo una frecuencia de 11 repeticiones, lo que equivalía al 3,7\% del total. Con esta categoría quisimos recoger manifestaciones, por parte de los entrevistados, relacionadas con el tiempo de implantación del proceso de formación virtual. A la luz de los comentarios tenemos que decir que estas experiencias se venían desarrollando en las universidades andaluzas desde, como mínimo, hace tres años.

El servicio funciona creo, desde hace para tres años. (ENTRE01.rtf - 1:1).

Aunque hay otras universidades en las cuales se trabajó en este tipo de entornos desde el año 99.

...fue en el 99, es la primera vez, aunque ya habia intentos aislados de algunos departamentos para tener sus páginas Web de la asignatura, por ejemplo, o de incluso algunos habian utilizado, ehh, blackboard. (ENTRE05.rtf - 5:1).

En el caso de la dimensión "Institución", esta categoría era más una categoría de tipo identificativo, de ahí su escasa frecuencia de aparición. En ella se recogía cuando el entrevistado nos decía la universidad en la que desempeñaba su tarea.

Por último, nos encontramos con la dimensión "Investigación/Evaluación", formada por una única categoría, con su mismo nombre, y que obtuvo una frecuencia de aparición muy escasa, aun teniendo en cuenta la importancia de este elemento. A la luz de lo comentado por los entrevistados, solo podemos destacar la realización de un estudio de necesidades encaminado a la mejora.

...nosotros sí hemos hecho una, un trabajo sobre diagnóstico de necesidades de formación del profesorado, que lo hicimos el año, el año pasado, y entonces sí que está ya el informe final... (ENTRE12.rtf - 12:11).

\section{3.- CONCLUSIONES.}

El estudio realizado nos permitió llegar a una serie de conclusiones: la primera de ellas, fue comprobar cómo se mostró un verdadero interés en todas las universidades andaluzas que participaron en la investigación por incorporar de forma general las TIC, y de manera particular, las redes telemáticas a los diferentes sectores de la vida universitaria: académica, de gestión y de investigación. Y ello lo podemos concluir ya que existió un aumento del interés de las universidades, progresiva implantación, e inversión constante de recursos (técnicos y humanos). Un dato que es similar a los alcanzados en otros estudios nacionales e internacionales, cuando también todos los actores a los cuales se les demandó la información eran distintos a los técnicos, es decir,

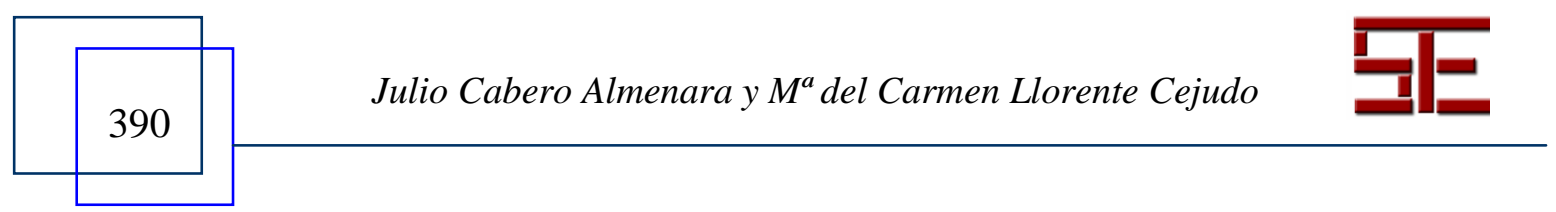




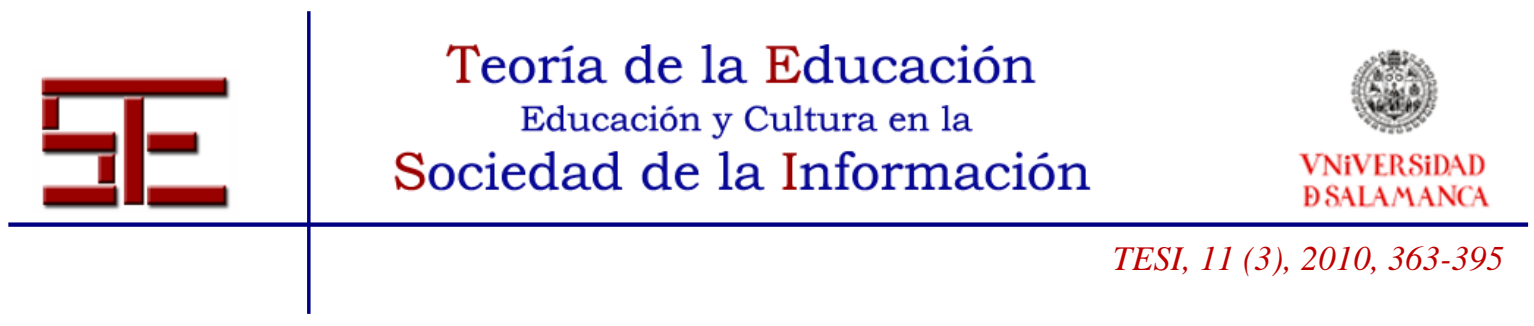

eran profesores y estudiantes (Duart y otros, 2008; Lu y Chion, 2009; Ginns y Ellis, 2009).

Nos resultó interesante que las preocupaciones fundamentales de los técnicos se refiriesen al profesorado, y más concretamente, por cómo incorporaban estas nuevas herramientas en sus actividades docentes. En contrapartida, las preocupaciones menores se dieron respecto a la investigación y evaluación de las experiencias, lo cual responde a la tipología de las personas entrevistadas.

Es también de destacar que otras de sus preocupaciones hacían referencia a cómo se fue desarrollando la implantación de la formación virtual. Aunque en este caso, resultó llamativo que aparecieran diferencias respecto a otros profesionales, como son los profesores. En este caso, los técnicos percibían que se realizaron grandes esfuerzos por parte de las universidades, y no tanto por parte de los profesores que siempre solían demandar más reacción por parte de las instituciones (Cabero, 2010).

Una de las grandes preocupaciones que se dio en las personas entrevistadas, se refería a si el profesorado contaba con capacitación suficiente para la utilización de estas tecnologías, y en este aspecto había una fuerte coincidencia entre las opiniones por nosotros aquí encontradas y otros estudios realizados con profesores (Blazquez y Alonso, 2009), que apuntaban a la necesidad de la misma.

Un fuerte acuerdo entre los técnicos, por un lado, y los profesores y los alumnos por otro, fue el que denotó un alto nivel de satisfacción por la utilización de este tipo de estrategias de formación (Duart y otros, 2008; Llorente y Cabero, 2008; Cabero y Llorente, 2009; Ellis y Goodyear, 2010). Estrategia que comnenzó a observarse como imparable en su puesta en acción en las universidades (Cabero, 2010).

Señalar que tal preocupación por la formación hizo que en todas las universidades andaluzas se llevasen a cabo acciones para la formación del profesorado.

Pero además, algunas universidades, con el objetivo de favorecer la penetración de las TICs, buscaron algún tipo de incentivo para que los profesores se incorporasen a la experiencia, yendo la gran mayoría en la dirección de facilitarle al profesorado ordenadores portátiles. Lo que no nos encontramos es que los incentivos fuesen de tipo económico.

De todas formas, existía una fuerte preocupación por dos hechos: uno, el que no todo el profesorado desease participar en este tipo de experiencias; y otro, que se dio un abandono de profesores que comenzaron y rechazaron la opción formativa. Respecto a los primeros, nuestro punto de vista es que no todo el profesorado tenía por qué utilizar

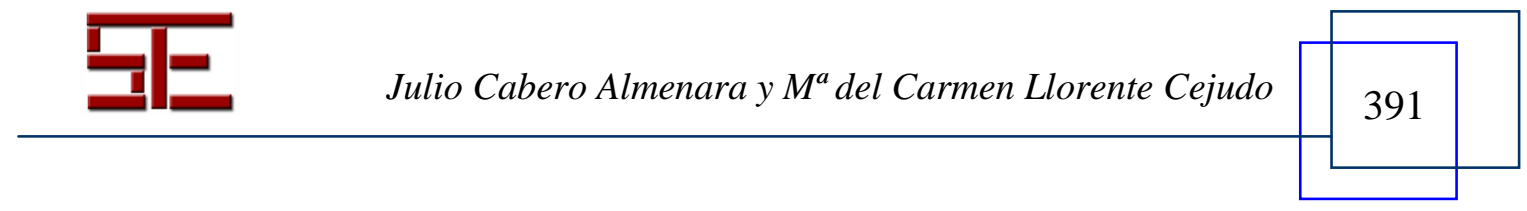




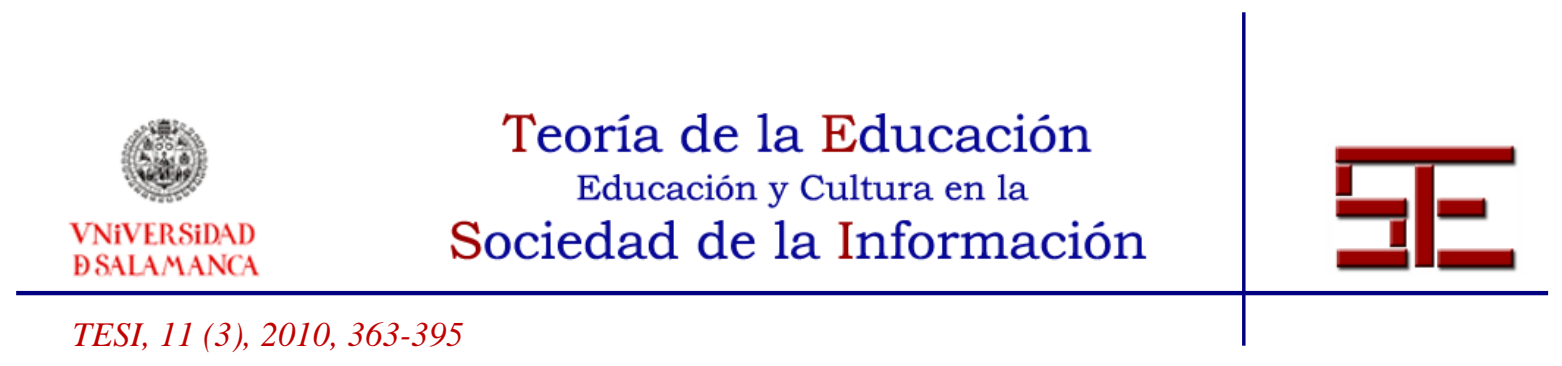

la misma opción formativa, y en lo que se refiere a lo segundo, muchas veces los errores provienen de las propias universidades que no se dan cuenta, que los profesores no tienen porque se técnicos, y no se les presta la suficiente ayuda, pensado que ellos por si mismos son capaces de virtualizar contenidos de calidad para las plataformas específicas, por poner un ejemplo.

En este último sentido, nos encontramos con universidades que tomaban direcciones en un doble sentido:

- Apoyo técnico al profesorado, no sólo para el manejo de la plataforma, sino para que construyese los contenidos de forma específica.

- Y la realización de Planes Específicos de apoyo al diseño de materiales por parte del profesorado.

En estos dos aspectos, posiblemente las experiencias más interesantes (por el volumen de actividades, su diversidad y recursos movilizados) nos las encontramos en la Universidad de Sevilla. De todas maneras, el apoyo de todas las universidades fue muy alto, tal como lo demuestra el volumen de intervenciones de los entrevistados que hacían referencia a la categoría "Apoyo institucional" dentro de la dimensión "Desarrollo de la formación virtual".

En lo que se refiere a la problemática de la plataforma virtual, la percepción de los técnicos nos demostró que la elección de la misma y su confiabilidad sigue siendo un problema existente en la mente de los responsables de la formación virtual. Ahora bien, resultó llamativo que dicha preocupación se observó en las entrevistas realizadas a las personas relacionadas con aspectos técnicos, y no ocurrió con los responsables que podríamos denominar de formación del profesorado o de la virtualización de los contenidos. Como alguna vez hemos señalado, lo importante no es la plataforma de teleformación utilizada, sino las estrategias educativas que movilicemos (Cabero y Llorente, 2005).

En este aspecto de la virtualización de los contenidos, nos pareció llamativo no encontrarnos referencia a la elaboración de libros de estilos para la presentación virtual de los mismos. Nos parece, teniendo en cuenta el volumen de cursos que se realizaban, que se cree que los mismos se podían resolver con la plataforma.

De todas formas, tenemos que reconocer que existía un interés en los entrevistados por identificar ejemplos de buenas prácticas que pudiesen ser puestos a disposición del resto de compañeros.

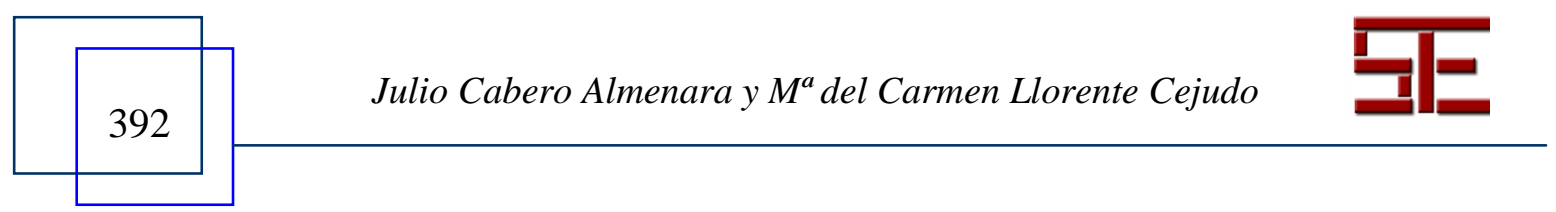




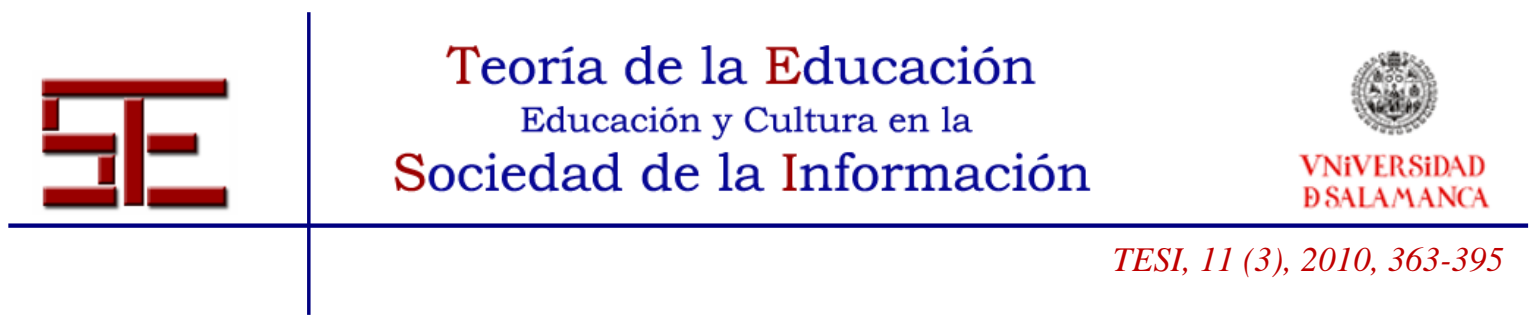

Por lo que respecta a los problemas técnicos que han ido apareciendo en la incorporación de la formación virtual en nuestras universidades, éstos han existido y no podemos olvidarnos de ellos, sobre todo los de conectividad. Pero sí tenemos que decir que en la actualidad nos informan que ellos se han resuelto progresivamente, por tanto, las preocupaciones deben ir en otras direcciones, como, por ejemplo: cómo aplicarla y para qué.

Por último, creemos necesario recoger en las investigaciones referidas al e-learning las opiniones de estos profesionales técnicos, pues, para bien o para mal, desempeñan una función importante en la incorporación de estas estrategias en las universidades, y del imaginario social que los profesores se crean respecto a sus posibilidades.

\section{4.- BIBLIOGRAFÍA.}

Albert, M. (2007). La investigación educativa. Madrid: McGraw-Hill.

Anderson, J. (1994). Context and text analysis. En Husen, T. y Postlethwaite, T.N. (ed). The international encyclopedia of education. vol. 4, (pp. 1074-1079). New York: Pergamon Press,

Bardin, L. (1977). Análisis de contenido. Madrid: Akal.

Benítez, R. y Aguilar, S. (2010). Situación del e-learning en las diferentes universidades públicas andaluzas. Edutec-e. Revista Electrónica de Tecnología Educativa, 31. Extraído el 20 de abril de, 2010, de http://edutec.rediris.es/revelec2/revelec31/.

Blázquez, F. y Alonso, L. (2009). Funciones de profesores de e-learning. Pixel-Bit. Revista de medios y Educación, 34, 205-215.

Bollinger, D.U y Wasilik, O. (2009). Factors influencing faculty satisfaction with online teaching and learning in higher education. Distance Education, 30, 1, 103-116.

Cabero, J. (dirs.) (2010). Usos del e-learning en las Universidades Andaluzas: estado de la situación y análisis de buenas prácticas. Sevilla: Grupo de Investigación Didáctica.

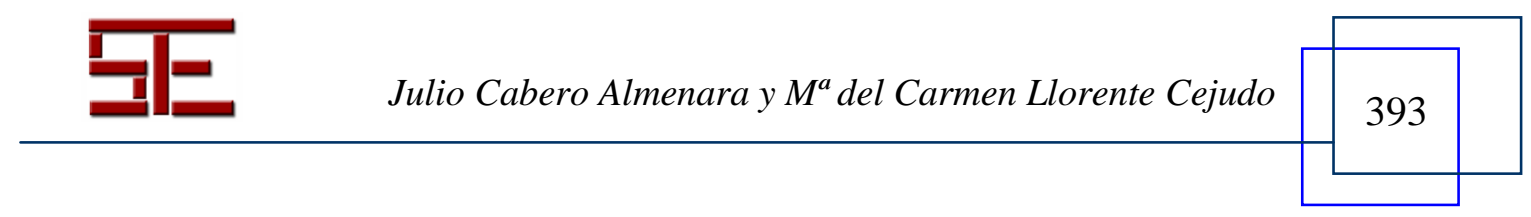




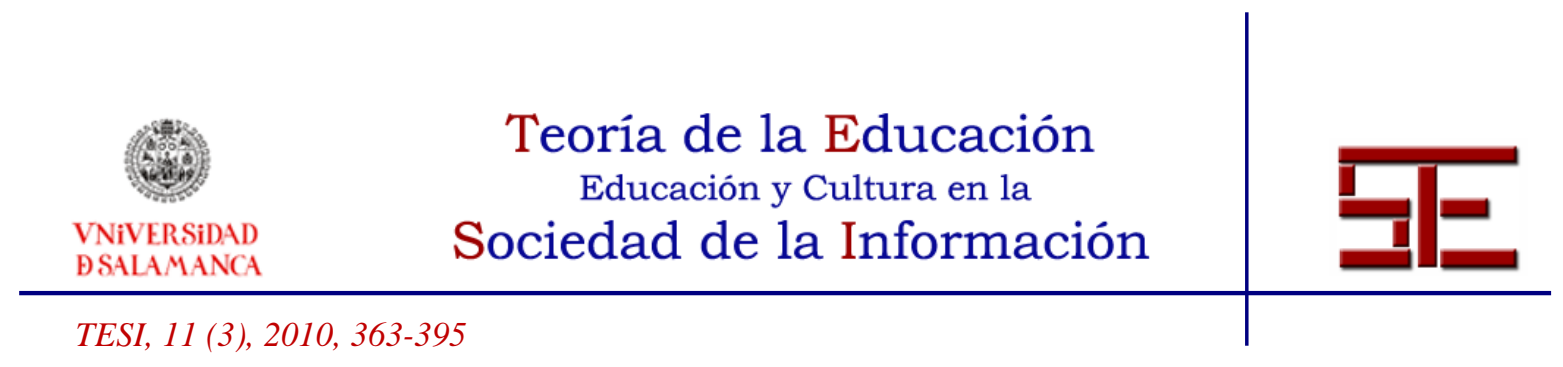

Cabero, J. y Llorente, M.C. (2005). Las plataformas virtuales en el ámbito de la teleformación. Revista electrónica Alternativas de educación y comunicación. Extraído el 8 de abril, 2007, de http://www.e-alternativas.edu.ar/.

- (2009). Actitudes, satisfacción, rendimiento académico y comunicación online en procesos de formación universitaria en blended learning. Revista Electrónica Teoría de la Educación: Educación y Cultura en la Sociedad de la Información. vol. 10, $n^{o}$ 1. Extraído el 6 de abril, 2009, de http://www.usal.es/ teoriaeducacion/rev_numero_10_01/n10_01_cabero_llo rente.pdf (6/04/2009).

Cabero, J. y Romero, R. (2010). Análisis de buenas prácticas del e-learning en las universidades andaluzas. Revista Electrónica Teoría de la Educación: Educación y Cultura en la Sociedad de la Información, vol. 11, $\mathrm{n}^{\mathrm{o}}$ 1, 283-309. Extraído el 1 de marzo, 2010, de

http://revistatesi.usal.es/ revistas_trabajo/index.php/revistatesi/article/view/6293/6306.

Clemente, M. y Santalla, Z. (1991). El documento persuasivo, Análisis de contenido y publicidad. Madrid: Ediciones Deusto.

Conole, G. y Oliver, M. (ed.) (2007). Contemporary perspectives in e-learning research. Themes, methodes and impact on practice. London: Routledge.

Correa, J.M. (2004). ¿Calidad educativa on-line?: Análisis de la calidad de la educación Universitaria basada en Internet. Pixel-Bit. Revista de Medios y Educación, 24, 11-42.

Duart, J.M. y otros (2008). La Universidad en la sociedad red. Usos de Internet en Educación Superior. Barcelona: Ariel.

Ellis, A. y Goodyear, P. (2010). Students' Experiences of e-leaning in Higher Education. London: Routledge.

Gannon, R. y otros (2009). Motivators and Inhibitors for University Faculty in Distance and e-learning. British Journal of Educational Technology, 40, 1, 149-163.

Ginns, P. y Ellis, R. (2009). Evaluating the quality of e-learning at the degree level in the student experience of blended learning. British Journal of Educational Technology, 40, 4, 652-663.

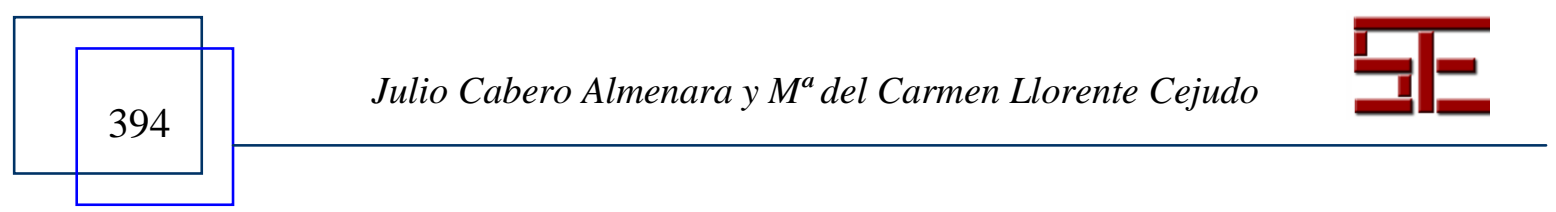




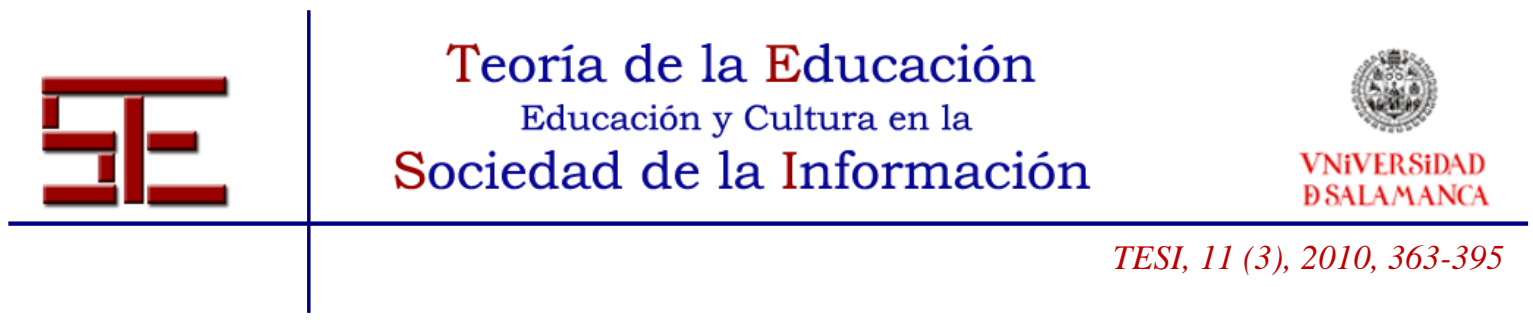

Llorente, M.C. y Cabero, J. (2008). La formación semipresencial a través de redes telemáticas (blended learning). Mataró: Da Vinci.

Lu, H.P. y Chiou, M. (2009). The impact of individual differences on learning system satisfaction: A contingency approach. British Journal of Educational Technology, 1, 17.

Pérez, M. (2008). Asignaturas virtuales en universidades presenciales: perspectivas y problemas. Pixel-Bit. Revista de Medios y Educación, 31, 187-198.

Pérez Serrano, G. (1984). El análisis de contenido de la prensa. Madrid: UNED.

Postic, M. y De Ketele, J.M. (1992). Observar las situaciones educativas. Madrid: Narcea.

Para citar el presente artículo puede utilizar la siguiente referencia:

Cabero Almenara, J. y Llorente Cejudo, M. C. (2010). Percepciones del e-learning desde la perspectiva de los responsables técnicos de universidad, en Orejudo González, J.P. (Coord.) Perspectiva educativa y cultural de "juego de rol". Revista Teoría de la Educación: Educación y Cultura en la Sociedad de la Información. Vol. 11, no 3. Universidad de Salamanca, pp. 363-395 [Fecha de consulta: dd/mm/aaaa]. http://campus.usal.es/ revistas_trabajo/index.php/revistatesi/article/view/7468/7485

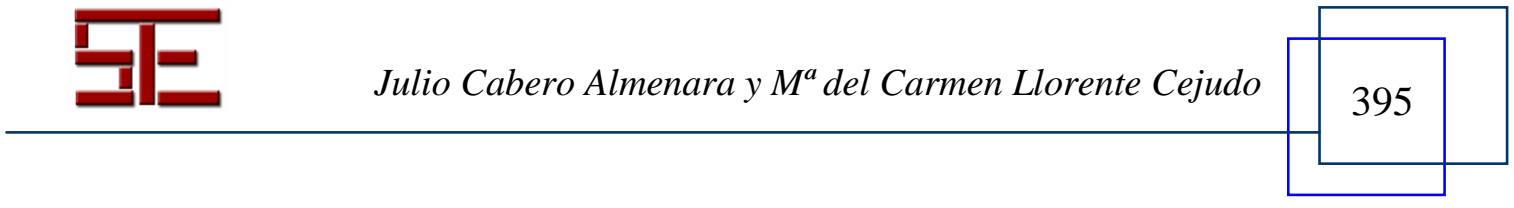

